Article

\title{
Hybrid Set Covering and Dynamic Modular Covering Location Problem: Application to an Emergency Humanitarian Logistics Problem
}

\author{
Roghayyeh Alizadeh ${ }^{1, *}$ and Tatsushi Nishi ${ }^{2, *}$ (i) \\ 1 Division of Mathematical Science for Social Systems, Department of Systems Innovation, Graduate School of \\ Engineering Science, Osaka University, Machikaneyama-Cho 1-3, Toyonaka City 560-8531, Osaka, Japan \\ 2 Graduate School of Natural Sciences, Department of Industrial Innovation Engineering, Okayama \\ University, Tsushima-naka 3-1-1, Kita-ku, Okayama City 700-8530, Okayama, Japan \\ * Correspondence: alizadeh@inulab.sys.es.osaka-u.ac.jp (R.A.); nishi.tatsushi@okayama-u.ac.jp (T.N.)
}

Received: 15 September 2020; Accepted: 9 October 2020; Published: 13 October 2020

\begin{abstract}
This paper presents an extension of the covering location problem as a hybrid covering model that utilizes the set covering and maximal covering location problems. The developed model is a multi-period model that considers strategic and tactical planning decisions. Hybrid covering location problem (HCLP) determines the location of the capacitated facilities by using dynamic set covering location problem as strategic decisions and assigns the constructive units of facilities and allocates the demand points by using dynamic modular capacitated maximal covering location problem as tactical decisions. One of the applications of the proposed model is locating first aid centers in humanitarian logistic services that have been addressed by studying a threat case study in Japan. In addition to validating the developed model, it has been compared to other possible combined problems, and several randomly generated examples have been solved. The results of the case study and model validation tests approve that the main hybrid developed model (HCLP) is capable of providing better coverage percentage compared to conventional covering models and other hybrid variants.
\end{abstract}

Keywords: covering location; multi-period; strategic and tactical planning; modular; maximal covering; set covering

\section{Introduction}

The covering location problem seeks to find the location of facilities like fire stations or shelter sites to cover the demand points within distance or time limits. It is one of the four major categories of facility location problems that consist of two main problems as set covering location problem (SCLP) and maximal covering location problem (MCLP) [1]. The most significant distinction of covering location problems with other models is the coverage radius of facilities that the points inside the coverage radius are potential to be covered, but the points out of the coverage radius cannot be covered. Given the coverage radius in the form of travel time or distance, SCLP aims to provide coverage for all points by finding the minimum number of facilities to be located. Covering all points is an ideal objective that might not be compatible with all systems, because in most of the management systems, the resources or budgetary limitations have to be taken into account. MCLP can be the appropriate model for these conditions when the demands points covered by the predefined number of facilities are maximized [2]. Both SCLP and MCLP have applications in the planning of both private and public sector facilities that have attracted many scholars due to their computational challenges and various real-world applications, such as locating emergency facilities in emergency humanitarian logistic 
services. During the five decades since the introduction of covering problems, many extensions of SCLP and MCLP have been developed, such as: tour and path covering SCLP, SCLP covering games, multi-coverage SCLP, generalized MCLP, gradual coverage MCLP, and hierarchical MCLP, in addition to back-up coverage, stochastic and probabilistic, and implicit and explicit models for both SCLP and MCLP. Interested readers can refer to [3-5] and [1] for reviews on covering facility location problems.

Extending the covering location models to a multi-period or dynamic structure is more common for MCLP [6-8] rather than SCLP. The reason is that SCLP provides full allocation of demand points from fixed located facilities, and there is no need to alter these locations in different time periods' decisions unless the problem is studied in the presence of demand fluctuation [9] and expansion possibilities for capacitated facilities. In dynamic MCLP, decision makers are interested in finding the optimal way of locating a definite number of facilities in different periods. The application of dynamic MCLP can be in locating emergency service centers in populated regions that on-road accidents may happen, and the number of facilities to be located may fluctuate between different periods of time because of daily traffic, the weather situation, etc. Moreover, each opened facility in the beginning of a time period can be closed at the end of that time period in a dynamic MCLP.

Hierarchical facility location problems use "hierarchy" to describe the problem as the coordination of location decisions for different type of facilities in multi-level systems [10]. For example, healthcare systems are one of the most studied systems in the literature [11]. The number of levels in healthcare facility systems varies such that, in a three-level example, there may exist demand points, local clinics, hospitals, and regional hospitals as different levels of facilities. Modularity is almost a newer concept that is utilized by the researchers to attain multi-level systems. In the field of location problems, the modularity concept is used to represent different types of facilities [12] or may be applied in arcs when there are different kinds of vehicles for transportation [13]. The main difference between modular and hierarchical facility location problems is that modular facility location problems can have more levels of facilities, because various types of modules, the number of them, and different sizes of modules may create a diversity of multi-level facilities.

Both SCLP and MCLP have advantages and disadvantages regarding the coverage they provide and the cost issues. SCLP guarantees full coverage but yields to a high cost of facility location. On the other hand, the cost issues are controllable in MCLP, but all points cannot be covered. To benefit from the advantages of SCLP and MCLP, in this study, the idea of hybridization of these two models in an integrated model is addressed. The hybrid model is a multi-period model consist of strategic and tactical planning decisions. Strategic planning decisions include the location of the capacitated facilities, and tactical planning decisions include module assignment and demand points allocation. Figure 1 shows a schematic illustration of strategic and tactical decisions that are taken in each time period. Strategic decisions reflect the long-term goals that are taken to retain the system more viable. Tactical decisions are made to meet mid time goals that contribute to strategic decisions. Tactical decisions can be taken to respond with a faster action compared to strategic decisions $[14,15]$. It is supposed that the facilities are only the piece of land with basic infrastructures that would be located using SCLP that cover all demand points in each strategic period in response to the fluctuating demands and capacitated facilities. After determining the located sites as the facilities, in each tactical period, the limited number of each module kind would be assigned to the facilities using modular MCLP to maximize the covered demands. As mentioned above, one of the main features of the hierarchical or modular concept is that the decisions of assignment can be made only for one time period, and the decisions can change for the later periods. This feature allows having a different arrangement of modules in each facility and in each tactical period in terms of module type, number, and size. Using this integrated framework, trying to cover all demand points in the upcoming strategic periods, more facilities can also be located as extension decisions as a response to the rising demand. As an integrated model, the objective of the proposed model in this paper is to maximize the profit gained from the income of covering demand points and the cost of locating facilities. 


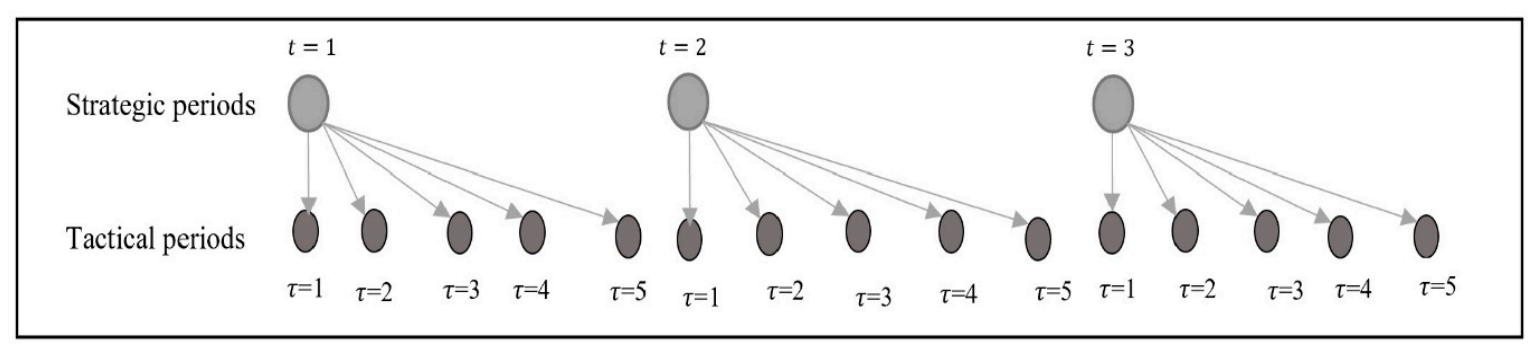

Figure 1. Strategic and tactical decision differentiation in the proposed model.

Similar to covering location problems, one of the main applications of the hybrid covering model is locating aid centers or evacuation sites in the humanitarian relief situation. The definition of the facility in this study is similar to the one that is used in real management systems, i.e., public facilities mainly with large yards, such as parks, schools, or parking lots [16] that can be utilized as an aid center in most of the disasters because of their low vulnerability. These kinds of facilities are usually equipped with essential needs such as water, electricity, etc. and are announced as shelter locations beforehand to the residents. Different kinds of modules can be considered, such as ambulances, trucks, helicopters, first aid units, food providing units, sleeping tents, shower rooms, etc. The importance of modularization of resources and services becomes apparent when, in most of the disasters, the whole area is exposed to be damaged, and if the facilities were located having full equipment, they might be out of order due to the disaster itself. Modularization can also have a high impact on budget management, as the modules can easily be dispatched to the other affected areas in the upcoming future. The other application of hybrid covering location problem is in locating hospitals, distribution centers, and integrated production planning and warehouse location problems [17].

The main contributions of this study are summarized as follows.

- In this paper, we try to benefit from the coverage concept of SCLP to locate the facilities (with the aim of providing access to the facilities for all demand points) and MCLP to locate the service providing units (with the aim of maximizing the coverage of demand nodes by the modules respecting the limited number of modules) in an integrated model.

- The integrated model is capable of improving the service quality and exploiting the limited number of modules in a better way compared to the non-integrated approach.

- Studying covering location problems in different decision levels as strategic and tactical decisions is not conducted before in the literature.

- In spite of the modeling advantage of modularity in providing multi-level facilities, it has received very limited attention in covering location problems. In this study, modular capacitated MCLP is developed to assign the service providing units to the facilities.

- A threat case study as an application of the developed hybrid model is studied, and other variants for possible hybridization models are presented and compared through numerical examples.

The remainder of the paper is categorized as follows. In Section 2, the literature review is presented. A review of SCLP and MCLP is included in Section 3. The mathematical formulation of the problem is presented in Section 4. In Section 5, the mathematical models of comparable models are discussed. Section 6 contains an application of the models and a case study with the results of the numerical examples. Finally, the paper is concluded in Section 7.

\section{Literature Review}

Toregas et al. [18] are the pioneers that developed the SCLP and solved the model by a linear relaxation technique using cuts to generate integer solutions. They also analyzed their model related to the p-median problem. Due to the difficulty in solving medium to large sizes of the SCLP, Murray and Wei [19] presented a computational approach to remove errors in the solution of SCLP, especially for 
the cases that utilize geographical information systems in applications like emergency warning sirens. The probabilistic SCLP was addressed by Borrás and Pastor [20], who investigated four possible models for SCLP by considering the assumptions of dependency and independency. Moreover, a mixed integer reformulation for probabilistic SCLP was developed by Saxena et al. [21], for which they presented some approaches to reduce the constraints in the developed model and to have stronger formulations. They evaluated their theoretical findings by conducting extensive instances.

A significant part of the literature of SCLP focuses on the application of SCLP in real-world problems. Vianna [22] considered the application of the SCLP in the optimization of gas detectors in process plants as a $0-1$ integer programming model in order to calculate the best location and the minimum number of gas detectors in a facility site. Another application of SCLP is to locate the traffic counting stations that are used to monitor the traffic flow of transportation vehicles in highways. This application was studied by Vieira et al. [23], with the objective of minimizing the total number of stations to cover all origin and destination nodes of the network, for which they proposed a hybrid algorithm based on exact, heuristic, and hybrid approaches that could solve an acceptable fraction of instances to find the optimal solution. Furthermore, Park et al. [24] presented the flight plans for unmanned aerial vehicles that can be very useful for rescue operations in disaster situations using quadratic constraints. As the SCLP in the presence of quadratic constraints is a complex problem to solve even for small size problems, the authors developed an approximation model that was solved by a branch and price algorithm. The optimal number and locations of pharmaceutical warehouses is another application of SCLP that was studied by Mokrini et al. [25]. They also conducted a sensitivity analysis to show how different coverage distances can affect the number of warehouses and the network configuration.

MCLP was presented by Church and ReVelle [26], and following their research, many researchers tried to improve MCLP models and developed many extensions of it. Probabilistic MCLP was studied by Corrêa et al. [27] and Pereira et al. [28]. A stochastic optimization model for a multi-service MCLP was presented by Taymaz et al. [29] with the objective of maximizing the total expected weighted coverage of the network. The authors integrated their model with a risk-averse approach in order to reduce the losses that can be resulted from lack of coverage and then validated their model using a real multi-disease case study in Africa. In addition, a robust formulation for MCLP with application in disaster relief that minimizes the maximal regret over all possible combinations of values for the columns benefit with the associated algorithms to solve the problem was presented by Coco et al. [30].

Doerner et al. [31] studied an MCLP in a real case study in Australia by having double-coverage. In their model, all demands are ensured to be covered inside a coverage radius and a proportion of demands to be covered inside a smaller radius. The maximum set $\mathrm{k}$-covering problem is to choose $\mathrm{k}$ columns out of total columns in such a way that the number of rows covered by the selected columns is maximized. This problem was addressed by Lin et al. [32], focusing mainly on solving methods of this complex extension of MCLP. Alizadeh and Nishi [33] developed a multi-period maximal hub location model that allows the number of located hubs to be expanded in upcoming time periods when the demands are increasing. As the authors have considered the customers' preferences in choosing the cheapest price for multiple carriers, their developed model is a bi-level model in a Stackelberg game framework, who used dual based and Karush-Kuhn-Tucker based reformulations to achieve single-level problem and solved the single level problem with a Benders decomposition-based method.

There are also many applications of MCLP in modeling real-life situations. Locating bicycle sharing stations in this way that users take the bikes, use them, and then return the bikes at the same or any other located stations were addressed by Muren et al. [34]. They considered a lower bound for the workload of each station that could also lead to improved results quality. By the appearance of rechargeable electric vehicles and addressing the need to build charging stations for these kinds of vehicles, Dong et al. [35] formulated and solve the problem of locating vehicles charging stations using MCLP and took into account the spatial information statistic of charging demand as a stochastic process. Similar to the application studied by Park et al. [26], Chauhan et al. [36] studied the problem of assigning 
the drones used for carrying the delivery packages in commercial services. Chauhan et al. [36] used MCLP to formulate their problem considering package weight, battery, and coverage constraints and developed a heuristic method to solve the problem with sensitivity analysis of the problem parameters. Furthermore, to locate ambulances in response to urban emergency requests, Kaveh and Mesgari [37] used MCLP in combination with an improved biogeographical-based optimization method. To refine the number of candidate locations for ambulance stations, they used geographic information system and the analytical hierarchy process method and compared the results of their developed solving procedure with similar methods. Nilsang et al. [38] studied the location of ambulance bases by utilizing MCLP and the real-time information obtained from social media like Twitter. They studied the reallocation of ambulances in response to demand fluctuation in a dynamic framework and validated the model by applying it to the emergency medical services in Bangkok. The problem studied in this paper has applications in locating facilities in disaster relief situations that will be specified in the following sections.

One of the assumptions of the basic MCLP is the binary coverage, which supposes a demand point to be covered completely if it is located within a critical distance or travel time of the facility, and if the demand point is outside of the critical distance or travel time, it cannot be covered by the facilities. Most of the researchers have found this assumption to be too restrictive, especially for the applications in emergency systems like the current study. Berman et al. [39], Drezner et al. [40], and Karasakal and Karasakal [41] are among those who studied the MCLP by modeling coverage as a gradual or partial coverage which means the coverage provided to a demand point decreases gradually with the increasing distance or travel time from a facility. Berman et al. [42] extended the gradual coverage to the case that the coverage can be provided from multiple facilities with applications in cell phone tower service providers. They tested several methods to solve the developed model, such as the greedy heuristic method, tabu search, ascent heuristic, and tangent line approximation method. Locating undesirable facilities like nuclear plants in the presence of gradual coverage was addressed by Khatami and Salehipour [43]. As the objective of undesirable facilities is contrary to the common commercial facilities, the model is called a minimal covering location problem that seeks to locate the facilities in places that covers a minimum number of residents.

In the literature, on covering facility location models, some concepts have been studied for both SCLP and MCLP. One of these concepts is the backup service that is addressed by Erdemir et al. [44], who considered both air and ground ambulances to provide services for emergency request modeling both SCLP and MCLP. Three coverage options were possible: only air ambulance, only ground ambulance, or a teamwork in such a way that the ground ambulance carries the patient to a place that can be reached by the air ambulance. Their model took into account the uncertainty in demands and used a greedy heuristic to solve the problem of a case study in New Mexico State. The uncertainty in response time and demands raising from an emergency situation was applied to SCLP and MCLP as separate models by Zhang et al. [45]. They developed two models for MCLP and one model for SCLP based on the fuzzy set theory. The service time in SCLP and the first variant of MCLP are considered to be uncertain; in this way, that the membership of response time is less than the coverage radius was set to be more than a specified value. On the other hand, the second variant of MCLP maximizes the chance of an uncertain event, i.e., a chance of coverage to be larger than a predetermined coverage level. To solve two variants of MCLP, the first variant can be reformulated as the second one for which they have developed a method to solve it using a case study in Sichuan, China. To solve very large-scale problems of partial SCLP and MCLP up to millions of demand points and obtaining an optimal solution for this huge size of problems, Cordeau et al. [46] presented a Benders decomposition method. The good performance of their method is due to the utilization of a Branch-and-Benders-cut algorithm.

Although some modeling ideas have been studied for both SCLP and MCLP, all of these studies have considered SCLP and MCLP as separate models. To the best of our knowledge, there is no study that has modeled SCLP and MCLP in an integrated model as the model developed in this paper. Table 1 reviews important models in the areas related to our study. Although there is no study combining 
SCLP and MCLP in one model, they are related to the model of this paper from at least one perspective. The decision level (last column of the Table 1) of the models might be not specified directly in the papers, but as the facility location problems generally belong to strategic decision levels, they have been classified as strategic decision models. The last row of Table 1 illustrates the contribution of this research compared to the literature.

Modularity is a strategy recognized by academia and industry and plays an important role in the development of sustainable systems [47]. The modular location problem is one of the important research streams of the current study, which is applied to facility location problems recently. For instance, Addis et al. [48] tackled a particular location problem, where two sets of facilities have to be located in which different devices can be installed at each site, providing different capacities with different costs. Moreover, Correia and Melo [12] presented a multi-period facility location problem with modular capacity adjustments and flexible demand fulfillment. In their research, customers were divided with different sensitivity to delivery lead times. They also proposed two mixed integer linear programming formulations and did an extensive numerical study on randomly generated data with different demand patterns. Yin and $\mathrm{Mu}$ [49] assumed the ambulances as the modules of the emergency service facilities and proposed two variants of the capacitated MCLP for fixed and unfixed number of facilities to be located. They formulated their model as a static model and utilized the geographical information system. Furthermore, Alizadeh and Nishi [50] developed the modular MCLP to locate the emergency facilities by considering backup services for the request of demand points. The backup service can be provided from other facilities in the coverage radius when the primary facility is busy providing service for other emergency calls. The authors developed a heuristic method and a genetic algorithm to solve the problems of large-scale problems.

Table 1. Related papers in the literature (classified based on modeling ideas).

\begin{tabular}{|c|c|c|c|c|c|c|c|}
\hline Paper & $\begin{array}{l}\text { Model } \\
\text { S,M,H }\end{array}$ & $\begin{array}{c}\text { Period } \\
\text { S,M }\end{array}$ & $\begin{array}{c}\text { Coverage Type } \\
\text { B,G,C }\end{array}$ & $\begin{array}{c}\text { Facility Type } \\
\text { S,M }\end{array}$ & $\begin{array}{c}\text { Data Modeling } \\
\text { D,S,F,R }\end{array}$ & $\begin{array}{c}\text { Capacity Constraint } \\
\text { C,N,M }\end{array}$ & $\begin{array}{c}\text { Decision Levels } \\
\text { S,T,O }\end{array}$ \\
\hline Toregas et al. [18] & $\mathrm{S}$ & S & B & S & $\mathrm{D}$ & $\mathrm{N}$ & S \\
\hline Rajagopalan et al. [9] & S & M & B & S & $\mathrm{D}$ & $\mathrm{N}$ & S \\
\hline Eiselt and Marianov [51] & S & $\mathrm{S}$ & G & S & $\mathrm{D}$ & $\mathrm{N}$ & S \\
\hline Berman et al. [52] & S & S & G & M & $\mathrm{D}$ & $\mathrm{N}$ & S \\
\hline Church and ReVelle [26] & M & S & B & $S$ & $\mathrm{D}$ & $\mathrm{N}$ & S \\
\hline Bagherinejad et al. [53] & M & S & $\mathrm{G}, \mathrm{C}$ & S & $\mathrm{D}$ & $\mathrm{N}$ & S \\
\hline Farahani et al. [54] & M & S & B & M & $\mathrm{D}$ & $\mathrm{N}$ & S \\
\hline Coco et al. [30] & M & S & B & $\mathrm{S}$ & $\mathrm{R}$ & $\mathrm{N}$ & $S$ \\
\hline Yin and $\mathrm{Mu}$ [49] & M & S & B & M & $\mathrm{D}$ & $\mathrm{C}$ & S \\
\hline Berman et al. [42] & M & $S$ & $\mathrm{G}, \mathrm{C}$ & $S$ & $\mathrm{D}$ & $\mathrm{N}$ & S \\
\hline Vatsa and Jayaswal [8] & M & M & B & $S$ & S & $\mathrm{C}$ & S \\
\hline Alizadeh Nishi [50] & M & M & G & M & $\mathrm{D}$ & $\mathrm{C}$ & S \\
\hline Zhang et al. [45] & $\mathrm{M}, \mathrm{S}$ & $S$ & B & $S$ & F & $\mathrm{N}$ & S \\
\hline Erdemir et al. [44] & M,S & S & B & M & $\mathrm{D}$ & $\mathrm{N}$ & S \\
\hline Proposed HCLP & $\mathrm{H}$ & M & G & M & $\mathrm{D}$ & $\mathrm{C}, \mathrm{M}$ & $S, T$ \\
\hline
\end{tabular}

Model: S (set covering location problem or SCLP), M (maximal covering location problem or MCLP), and H (Hybrid). Period: S (Single period) and M (Multi-period). Coverage Type: B (Binary), G (Gradual), and C (Cooperative). Facility type: S (Single) and M (Multiple/Modular). Data Modeling: D (Deterministic), S (Stochastic), F (Fuzzy), and R (Robust). Capacity Constraints: C (Capacitated), N (Noncapacitated), and M (Module capacity). Decision level: S (Strategic), T (Tactical), and O (Operational).

The next sections provide more information about the mathematical formulations of basic SCLP and MCLP and assumptions and definitions of the hybrid covering the location problem.

\section{SCLP and MCLP}

In this section, the mathematical formulations of SCLP and MCLP are firstly presented, because these models will be utilized in the formulation of the hybrid covering location problem. After that, the assumptions and formulation of the hybrid covering location problem will be presented in the next section.

Set covering location problem (SCLP) and maximal covering location problem (MCLP) were introduced in 1971 and 1974 by Toregas et al. [18] and Church and ReVelle [26], respectively. In the 
original set covering location problem, a facility can serve all demand points that are within a given coverage distance from the facility. The problem is finding the minimum number of facilities to ensure that all demand points can be served. In this model, there are no capacity constraints for the facilities. The demand points are represented by the set of $j \in J$, and the possible locations of the facilities are given by the set of $i \in I$. dis $i j$ is the distance between potential facility $i$ and demand point $j$. Having the coverage distance $\rho$, one can generate the possible facilities that can cover demand points in a binary parameter $\sigma_{i j}$ that gets the value 1 if $d i s_{i j} \leq \rho$ and 0 , otherwise. The decision variable $\chi_{i}$ is a binary variable that is 1 if a facility is located in $i$ and 0 , otherwise. The mathematical model for original SCLP is:

$$
\begin{gathered}
\min \sum_{i \in I} \chi_{i} \\
\sum_{i \in I} \sigma_{i j} \chi_{i} \geq 1 \\
\forall j \in J \\
\chi_{i} \in\{0,1\} \\
\forall i \in I
\end{gathered}
$$

The objective function (1) minimizes the number of located facilities, and the constraints (2) implies that every demand point $j$ needs to be served by at least one facility. If there is a budget or resource limitation and one desires to locate $\varphi$ predefined facilities with the objective of maximizing the covered demand points, the problem is called the maximal covering location problem, for which, in addition to the introduced variable for SCLP, another decision variable is needed. $\gamma_{j}$ is a binary variable that is 1 if demand point $j$ is covered and 0 , otherwise. The mathematical model of MCLP is:

$$
\begin{gathered}
\max _{j \in J} \gamma_{j} \\
\gamma_{j} \leq \sum_{i \in I} \sigma_{i j} \chi_{i} \\
\forall j \in J \\
\sum_{i \in I} \chi_{i}=\varphi \\
\chi_{i}, \gamma_{j} \in\{0,1\} \\
\forall i \in I, j \in J
\end{gathered}
$$

The objective function (3) maximizes the number of covered demands. Constraints (4) allow each demand point to be covered only if there is a facility or more in the coverage distance from it. Constraint (5) fixes the number of located facilities to be equal to $\varphi$. The covering concepts provided with SCLP and MCLP would be utilized to formulate the hybrid covering location model that will be outlined in the next section.

\section{Hybrid Covering Location Problem Formulation}

In this section, a mixed integer linear programming model for the hybrid covering location problem (HCLP) is presented. The mathematical model integrates the coverage concept of capacitated SCLP and modular MCLP as strategic and tactical planning decisions, respectively. The objective of our model is to maximize the profit obtained from covering demand points and subtracting the cost of facilities location. The constraints of the model are the full coverage of all points by the facilities in a way that the total allocated demands to the facilities do not exceed the capacity of the facilities. We suppose that, as a real fact, the number of demand points and their demands may increase during the time horizon; then, the number of located facilities can expand to guaranty the full coverage of 
points. Other constraints of the model are the total number of each kind of assigned module to the facilities, the capacity of each module, and not to provide coverage for each point more than its need. Some of the most important decisions in the proposed model are as follows:

- Location, number, and establishment time of facilities is strategic periods during the planning horizon.

- Type and number of each module assigned to the located facilities in tactical periods of each strategic period during the planning horizon.

- Percentage of the allocate demand of points to the assigned modules in tactical periods of each strategic period during the planning horizon.

The main assumptions to develop the model are as follows:

- The problem is studied in a multi-period framework. The total planning horizon is classified into two types of periods as the strategic periods and tactical periods. Each strategic period is composed of several tactical periods with different kinds of decisions to be made.

- The facilities are supposed to be a piece of land or site, equipped with some initial infrastructures. The locations of these facilities are going to be decided only in strategic periods using the coverage concept of SCLP to determine the minimum number of facilities to be located with the aim of covering all demand points. Once a facility is opened in a strategic period, it cannot be closed and should continue its operation in future periods. In addition, the facilities are supposed to be capacitated, and the number of facilities can be expanded in response to the demand variation in the upcoming strategic periods.

- We suppose that there are different kinds of service providing units, namely the modules of facilities that are limited in terms of numbers and capacities. These modules can move to the facilities and should be assigned to the facilities in tactical periods. The optimal decisions of the module assignment to the facilities are supposed to obey the coverage concept provided with multi-period modular MCLP. The arrangement of modules in facilities can be varied in different tactical periods according to the points' demand fluctuation in order to maximize the amount of total covered demands.

- Each module comes in different sizes. It can be chosen from different sizes to increase the service quality offered to demand points to overcome the service shortages or having idle units.

- The modules are portable, and they can be transferred among the facilities when there is more request in another facility. The transferability is an important specification of modularity design that yields to flexibility in the system and reduces costs. The portability of most modules helps to provide a good level of service to demand points without having to provide more modules.

- It is supposed that covering the demand points by the modules obeys the gradual coverage concept using a partial coverage function. In a gradual coverage function, the demand points inside the full coverage radius can be covered completely, but by increasing the coverage radius, the amount of coverage decreases and the points outside the partial coverage radius are supposed not to be covered.

The notation for the model is as follows.

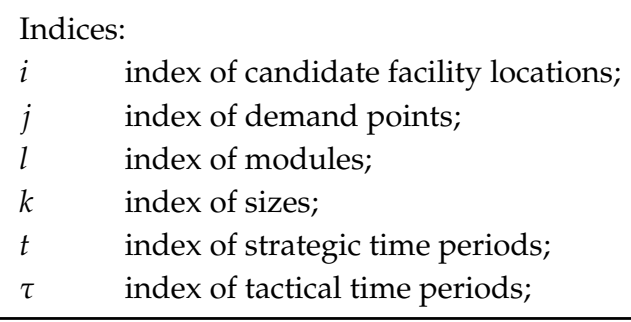




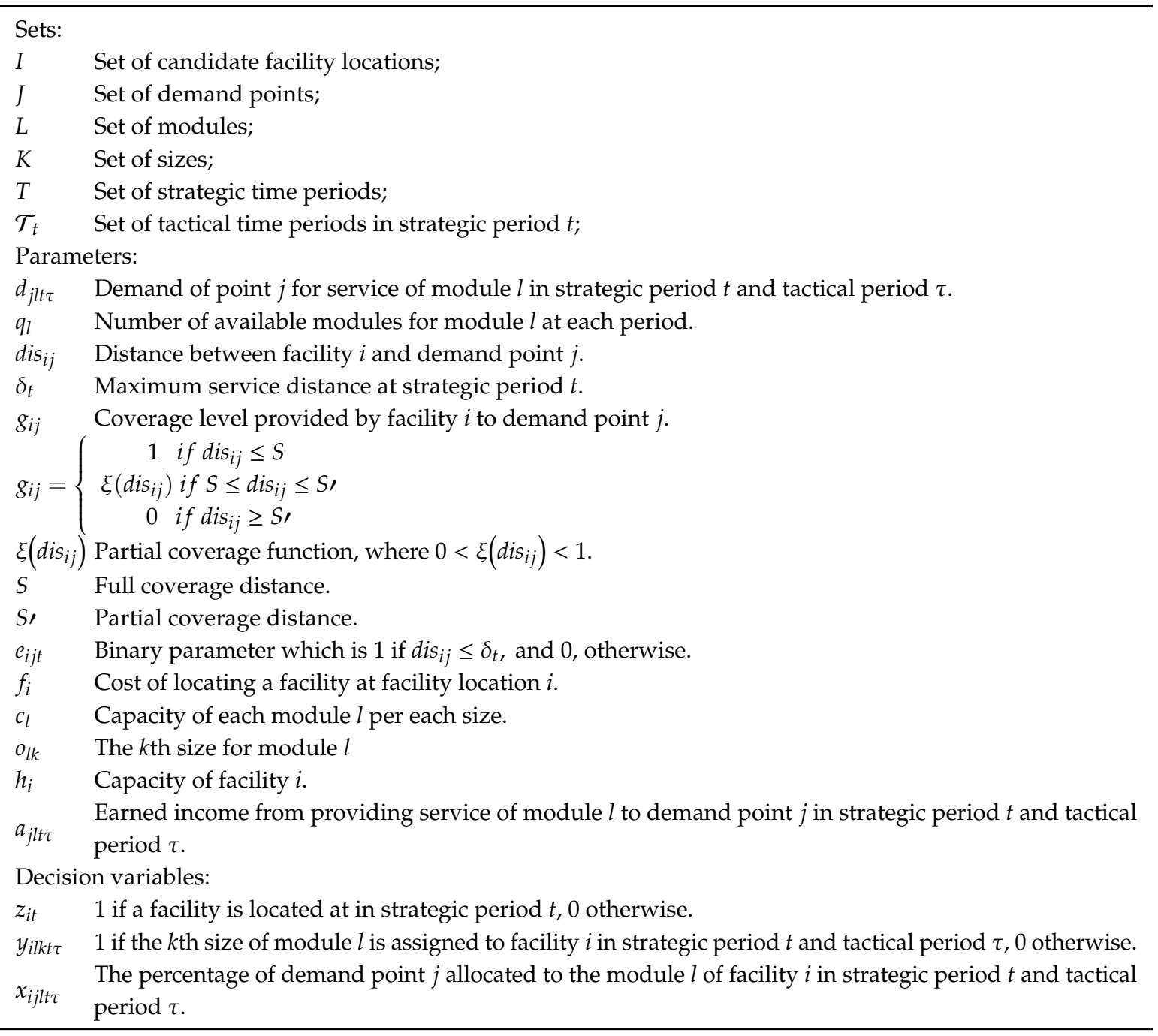

To locate the facilities by using the coverage concept of SCLP in different strategic periods, it is supposed that $d_{j l 1 \tau} \leq d_{j l 2 \tau} \leq \ldots \leq d_{j l T \mid \tau} \forall j, l, \tau$ and $\delta_{1} \geq \delta_{2} \geq \ldots \geq \delta_{|T|}$. This assumption is mandatory for modeling the problem, which implies that the demands are assumed to be increasing during the time horizon and while the coverage radius is fixed or decreasing in response to the increasing demand. We formulate the hybrid covering location problem (HCLP) as follows:

$$
\begin{gathered}
\max \sum_{i \in I} \sum_{j \in J} \sum_{l \in L} \sum_{t \in T} \sum_{\tau \in \mathcal{T}_{t}} a_{j l t \tau} g_{i j} d_{j l t \tau} x_{i j l t \tau}-\sum_{i \in I} \sum_{t \in T} f_{i} z_{i t} \\
\sum_{i \in I} e_{i j t} z_{i t} \geq 1 \\
\forall j \in J, t \in T \\
z_{i t} \leq z_{i t+1} \\
\forall i \in I, t \in T \\
\sum_{k \in K} y_{i l k t \tau} \leq z_{i t} \\
\forall i \in I, l \in L, t \in T, \tau \in \mathcal{T}_{t} \\
\sum_{k \in K} y_{i l k t \tau} \leq z_{i t} \\
\forall i \in I, l \in L, t \in T, \tau \in \mathcal{T}_{t}
\end{gathered}
$$




$$
\begin{gathered}
\sum_{i \in I} x_{i j l t \tau} \leq 1 \\
\forall j \in J, l \in L, t \in T, \tau \in \mathcal{T}_{t} \\
\sum_{i \in I} \sum_{k \in K} o_{l k} y_{i l k t \tau} \leq q_{l} \\
\forall l \in L, t \in T, \tau \in \mathcal{T}_{t} \\
\sum_{j \in J} d_{j l t \tau} x_{i j l t \tau} \leq \sum_{k \in K} o_{l k} c_{l} y_{i l k t \tau} \\
\forall i \in I, l \in L, t \in T, \tau \in \mathcal{T}_{t} \\
\sum_{j \in J} \sum_{l \in L} d_{j l t \tau} x_{i j l t \tau} \leq h_{i} z_{i t} \\
\forall i \in I, t \in T, \tau \in \mathcal{T}_{t} \\
z_{i t,}, y_{i l k t \tau} \in\{0,1\}, 0 \leq x_{i j l t \tau} \leq 1 \\
\forall i \in I, j \in J, l \in L, k \in K, t \in T, \tau \in \mathcal{T}_{t}
\end{gathered}
$$

The objective function (6) maximizes the profit that is the income gained from covering demand points subtracting the cost of locating facilities. Constraints (7) are the well-known constraint of SCLP that indicates all the points in each strategic period should be allocated to the facilities. Constraints (8) state that if a facility is opened in a strategic period, it should continue its operation for the forthcoming periods. Constraints (9) imply that modules can just be assigned to the open facilities, and in each facility, only one size of each module is allowed, while constraints (10) imply the same concept for the demand points in this way that the demand points can just be allocated to the assigned modules in each tactical period of strategic periods. Constraints (11) indicate that the total percentage of coverage provided for each demand point from all facilities should not exceed 1. Constraints (12) set the total number of modules assigned to the facilities to be less than the available number of modules i.e., $q_{l}$. Constraints (13) and (14) are capacity constraints of the modules and facilities, respectively. The left-hand side of the Constraints (13) calculates the total amount of allocated demands to each module in each facility, and the right-hand side keeps the total capacity that the assigned module of a specific size can provide. The left-hand side of the Constraints (14) calculates the total amount of allocated demands to all assigned modules for each facility. This amount, which is the overall allocated demands to each facility, should not exceed the capacity limit of the facility. Constraints (15) set the variables of location and module assignment to be binary variables, while the variables of demand allocation are set to be continuous.

\section{Comparison with Other Models}

There are other potential ways to combine SCLP and MCLP to shape the hybrid model. In the developed model of HCLP, SCLP is used to locate the facilities as strategic decisions, and MCLP is used to find the assignment of modules and demand allocation as tactical decisions. In the same way, MCLP-MCLP may refer to the case that both strategic and tactical decisions are determined using MCLP, SCLP-SCLP refers to the case where both strategic and tactical decisions are determined using SCLP, and finally, MCLP-SCLP refers to the model that strategic decisions are taken using MCLP and tactical decisions by using SCLP. These four models are comparable, because the solution variables are the same in all four models (except the number of located facilities that can be obtained from SCLP). Besides the same solution, the goal of covering problems, which is to cover more demand points, can be extracted from all four models as the coverage percentage. In this section, the mathematical model for each of these variants is developed, and in Section 7, the numerical examples are conducted to evaluate these models in terms of the coverage they provide and efficiency (elapsed time). Figure 2 shows these different possible hybridization problem structures. 


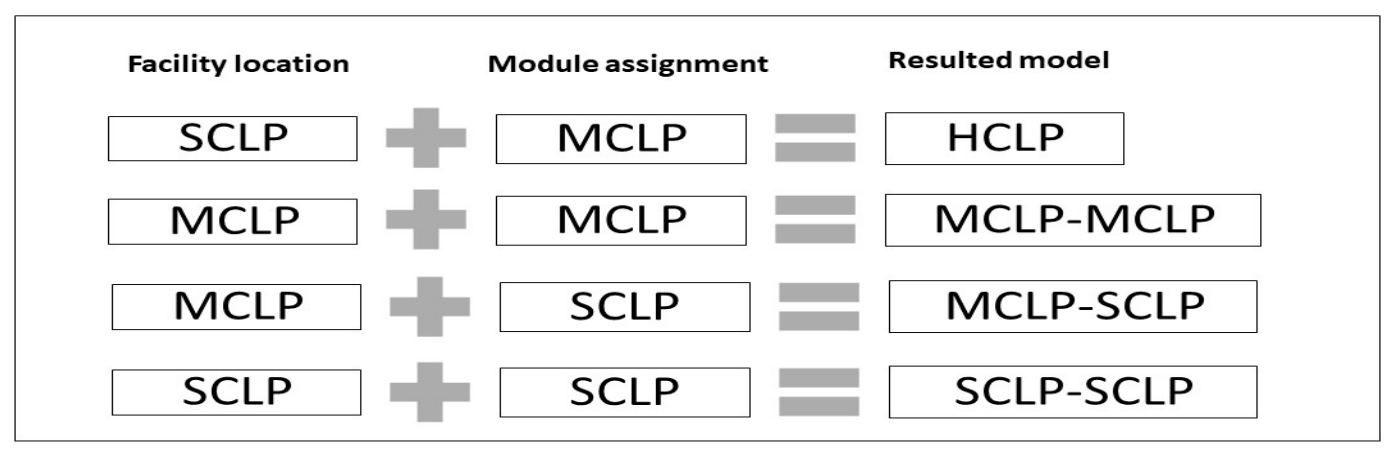

Figure 2. The structure of different possible hybridization models. SCLP: set covering location problem, MCLP: maximal covering location problem, and HCLP: hybrid covering location problem.

\subsection{MCLP-MCLP}

If we assume that the facilities are located using MCLP having a predefined number of them and the module assignment and demands allocation are modeled using MCLP, then the formulation of this problem is different from HCLP. MCLP-MCLP locates the facilities utilizing MCLP, and the decisions for module assignment and demand points allocation are determined by MCLP as well. In contrast to the HCLP that gives the solution to both numbers and location of the facilities, the number of the facilities in MCLP-MCLP is a parameter, and the problem only finds the optimal location of these predefined number of facilities. In addition, while the goal of HCLP is to cover all demand points by the facilities, this goal is not valid anymore in MCLP-MCLP, and it only seeks to maximize the total covered demand points. The main difference of HCLP and MCLP-MCLP is the constraint (7) that should be substituted by constraint (17) that implies the total number of located facilities in each strategic period cannot exceed the number defined beforehand. As mentioned before, the main motivation of using MCLP for locating facilities can be the budgetary limitations when the decision makers can afford only to open a specific number of facilities and look for the optimal location of these facilities with the aim of maximizing the demand points covered by them. In MCLP-MCLP, both the number of facilities and modules are a given problem parameter, and the model has to find the solution for their location and assignment. As a result, the objective of the MCLP-MCLP is just to maximize the profit gained from covering demands i.e., the cost of facilities is no longer included in the objective function. Thus, the difference between MCLP-MCLP and HCLP is in the objective function and constraints (7), and the mathematical formulation of the MCLP-MCLP can be modified as follows:

$$
\begin{gathered}
\max \sum_{i \in I} \sum_{j \in J} \sum_{l \in L} \sum_{t \in T} \sum_{\tau \in \mathcal{T}_{t}} a_{j l t \tau} g_{i j} d_{j l t \tau} x_{i j l t \tau} \\
\sum_{i \in I} z_{i t} \leq p_{t} \\
\forall t \in T
\end{gathered}
$$

(8)-(15).

where $p_{t}$ is the number of predefined facilities for each strategic period that is defined by the decision-makers as a parameter. Note that having the number of located facilities depending on the time periods is to keep the expansion capabilities of the model. Otherwise, it can be a fixed number for all periods.

\subsection{MCLP-SCLP}

This model's structure exploits the coverage concept of covering problems in a contrary format to HCLP model. In MCLP-SCLP, it is supposed that facilities obey the coverage concept of MCLP having specified numbers as strategic decisions, while the minimum number of modules has to be determined 
by SCLP in order to provide full coverage for each point from each module type as tactical decisions. The mathematical model of MCLP-SCLP has a similar formulation to MCLP-MCLP for facility location part, but the difference is in constraints (12) that should be replaced with constraints (19) that indicated each module type should be assigned to the opened facilities in a way that can provide full coverage for each demand point in each tactical period of strategic period. As a result, the objective of the MCLP-SCLP maximizes the profit obtained from the income of covering demand points and the cost of assigning the modules. The mathematical formulation of MCLP-SCLP is as follows:

$$
\begin{gathered}
\max \sum_{i \in I} \sum_{j \in J} \sum_{l \in L} \sum_{t \in T} \sum_{\tau \in \mathcal{T}_{t}} a_{j l t \tau} g_{i j} d_{j l t \tau} x_{i j l t \tau}-\sum_{i \in I} \sum_{l \in L} \sum_{k \in K} \sum_{t \in T} \sum_{\tau \in \mathcal{T}_{t}} b_{i l k t \tau} y_{i l k t \tau} \\
\sum_{\substack{i \in I \\
\forall \in K}} e_{i j}^{\prime} y_{i l k t \tau} \geq 1 \\
\forall j \in J, l \in L, t \in T, \tau \in \mathcal{T}_{t}
\end{gathered}
$$

$$
\text { (17), (8)-(11), (13)-(15). }
$$

where $b_{i l k t \tau}$ is the cost of assigning the size $k$ of module $l$ to the facility $i$ at tactical period $\tau$ of strategic period $t$, and $e_{i j}^{\prime}$ is the binary parameter, which is 1 if $d i s_{i j} \leq S$ and 0 , otherwise.

\subsection{SCLP-SCLP}

In SCLP-SCLP, both the facility location and modules assignment decisions are determined using the coverage concept of SCLP in a way that we desire to provide the full coverage of points from facilities in strategic periods and from each module type in tactical periods of strategic periods. Among all models, the SCLP-SCLP model can be implied as the model that has no limitation on the number of located facilities and modules, which is predicted to provide more equitable solutions. In contrast to the objective function of other defined models, the objective of SCLP-SCLP minimizes the cost of facility location and module assignment. To follow SCLP's theoretical perspectives, the objective function does not include the term for maximizing the coverage of the demands. The mathematical formulation of the SCLP-SCLP model is as follows:

$$
\begin{gathered}
\min \sum_{i \in I} \sum_{t \in T} f_{i} z_{i t}+\sum_{i \in I} \sum_{l \in L} \sum_{k \in K} \sum_{t \in T} \sum_{\tau \in \mathcal{T}_{t}} b_{i l k t \tau} y_{i k k t \tau} \\
\text { (7)-(11), (13)-(15), (19). }
\end{gathered}
$$

\section{Experimental Tests}

\subsection{Case Study: Application of HCLP in Humanitarian Logistic Services}

According to the latest report of the Centre for Research on the Epidemiology of Disasters (CRED) [55], "in 2019, at least 396 natural disasters were reported, killed 11,755 people, affected 95 million others and costing nearly 130 billion US dollars. Floods, storms and droughts accounted for almost $99 \%$ of the total number of affected people". More importantly, the report indicates that "the number of events in 2019 was slightly over the average of the last 10 years". The highest priority in these kinds of situations is to help the survivors. Despite the unknown occurrence time and the place of the natural disasters, emergency preparedness and response activities should be conducted as pre-disaster and post-disaster actions. One of the applications of the proposed HCLP model is locating aid centers and module assignment that can improve the impact of strategic and tactical relief operations in humanitarian situations caused by disasters such as earthquakes, floods, storms, wars, medical epidemic emergencies, and droughts. According to the Disaster Operations Management (DOM) framework [56], disaster operations are usually categorized into four main phases as mitigation, preparedness, response, and recovery, as shown in Figure 3. The application of HCLP in the humanitarian facility location problem, in which the location of the capacitated aid centers 
is determined as a strategic decision, belongs to the preparedness activity phase. In the response phase, the assignment of the service providing units to the located aid centers with the objective of maximizing the covered demand of affected people is determined. From Figure 3, the decisions during mitigation and preparedness activities can be regarded as strategic decisions, the decisions during the response activity can be regarded as tactical decisions, and in the same way, the decisions during recovery phase are assumed as operational decisions. The gray filled part illustrates the domain of HCLP in humanitarian services, which includes the strategic and tactical decisions of preparedness and response phases.

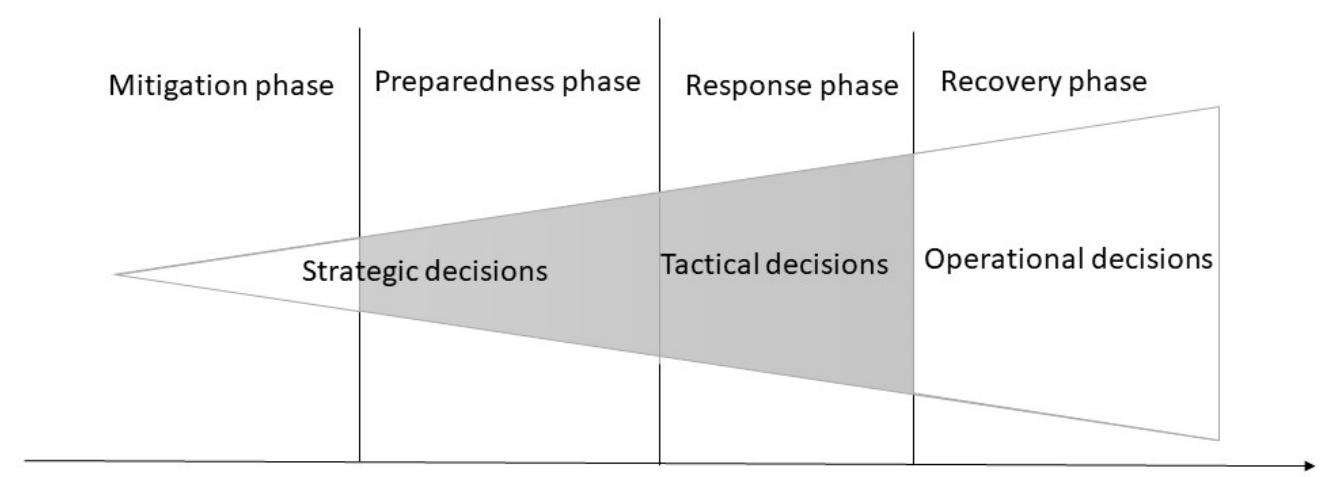

Figure 3. Different disaster operational phases and supply chain decision categories.

From an economical point of view, siting relief facilities and equip them with whatever is necessary to provide services for all affected areas after an unknown disaster is not efficient and may be impossible. To overcome the uncertainty in time and place of the disasters and the scarcity of the resources, the problem of this case study is to determine the location of relief facilities in some public schoolyards, parks, parking lots, etc. with the aim of minimizing the number of facilities covering all demand points inside the coverage radius. The decisions of locating facilities are determined as a strategic preparedness activity before disasters happen, and when a disaster happens in any region, the government or any responsible organization can dispatch the limited modules (trucks, helicopters, medical services, mobile kitchens, shelter tents, etc.) to the located facilities to start service operations there. When the modules fulfill their operations, they can be dispatched to be assigned to the other facilities of other affected regions according to the demand requests. In this case study, it is supposed that, in each strategic period, one of the areas in South-Central (R1), North-Central (R2), and the Center (R3) of Japan are affected by a disaster requesting for services provided by the modules in tactical periods. Each tactical period is equivalent to one month, and each strategic period is composed of three tactical periods. The North-Central part (R2) can correspond to the Japan 2011 earthquake. The number of 160 points matching the cities with more than 150,000 inhabitants according to census results and the latest estimates [57] is considered as demand points and, also, as the potential locations for locating facilities. There are four kinds of modules with four possible sizes, three strategic periods each composed of three tactical periods. Parameters $q_{l}, c_{l}, f_{i}$, and $h_{i}$ are generated randomly using uniform distribution between (30 and 50), (200,000 and 300,000), (700,000 and 900,000), and (4,000,000 and 6,000,000), respectively. As mentioned in the assumptions of the model and as a real-life fact, when a disaster hits a region, the modules dispatch to that area to provide service for demands requests until the end of the tactical periods, and in the next strategic period, as the new disaster occurs, they leave toward the newly affected area for the new mission. Therefore, in this case study, the threat scenarios are designed in this way that firstly one disaster hits the South-Central (R1) in the first strategic period; the second disaster occurs in the North-Central part (R2) in the second strategic period, and in the third strategic period, it is the Central part (R3) that is affected by a disaster and needs the modules assignment. 
Figure 4 shows the demand points in green color and the located facilities in blue in the last strategic period. The arrows show the flow of the modules from previously affected areas to the newly affected one to provide service. The blue circles have been used to demonstrate the affected areas. According to the solution of the problem for these threats, the first area (R1) affected by the disaster could cover $86.8 \%$ of the demands, the coverage for the second area (R2) was $99.6 \%$, and in the last affected area (R3), the coverage of demand points was $43.3 \%$ by the limited number of available modules. Table 2 includes the results of this case study in the second row. The coverage percent is calculated as:

$$
\frac{\sum_{i, j, l, t, \tau} g_{i j} d_{j l t \tau} x_{i j l t \tau}}{\sum_{j, l, t, \tau} d_{j l t \tau}}
$$

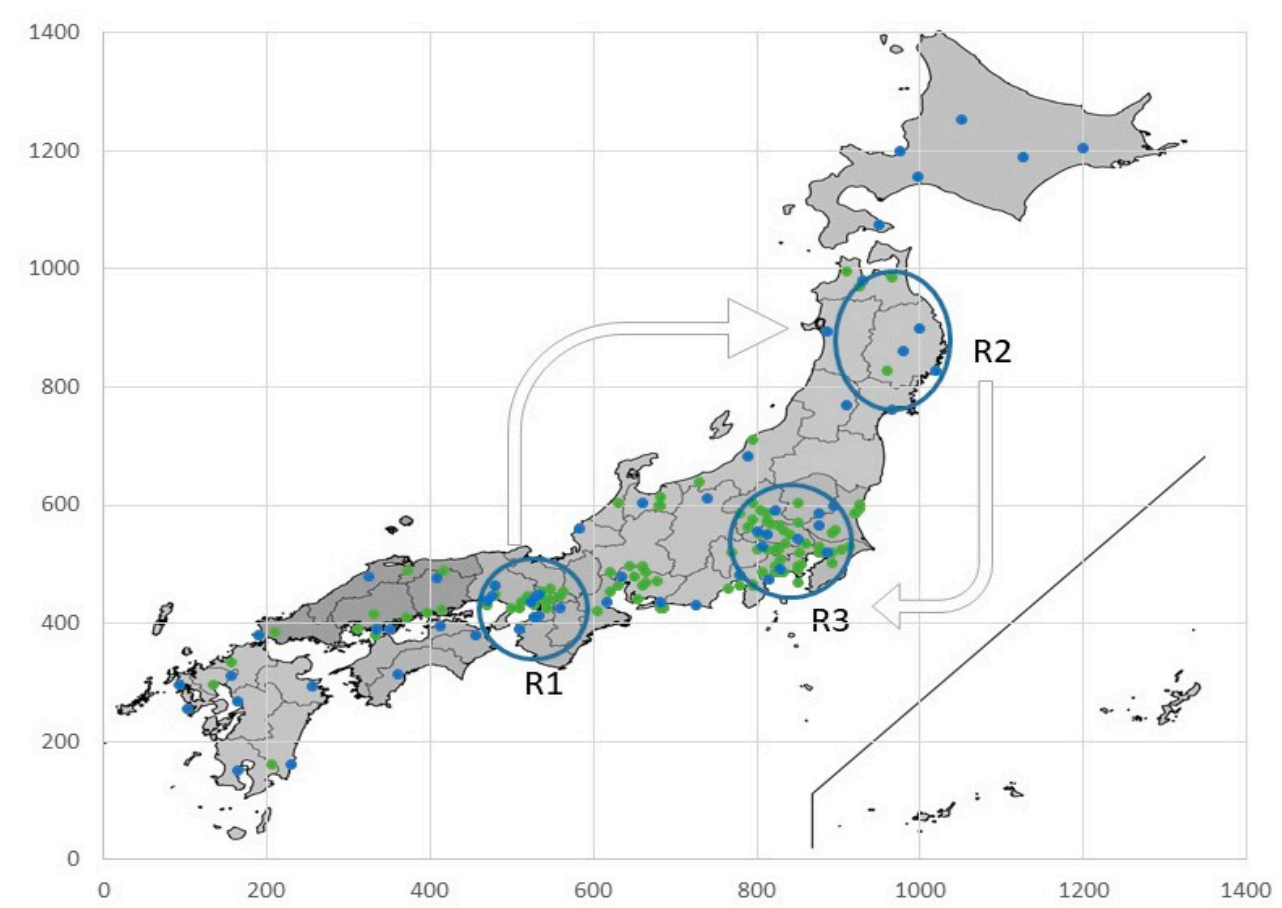

Figure 4. The demand points and facilities located at the last strategic period.

Table 2. Computational results of case study and sensitivity analysis.

\begin{tabular}{|c|c|c|c|c|c|c|}
\hline Problem Data & $\begin{array}{l}\text { Operating Facilities in R1, R2, } \\
\text { and R3 }\end{array}$ & Coverage $\%$ & $\mathbf{M Z}$ & MY & Obj & Time \\
\hline $\begin{array}{c}q_{l}: \mathrm{U}(30,50) \\
c p_{l}: \mathrm{U}(200 \mathrm{k}, 300 \mathrm{k}) \\
f_{i}: \mathrm{U}(70 \mathrm{k}, 90 \mathrm{k}) \\
h_{i}: \mathrm{U}(4 \mathrm{M}, 6 \mathrm{M})\end{array}$ & $\begin{array}{c}\text { R1: Amagasaki, Izumi, } \\
\text { Kakogawa, Kawanishi, } \\
\text { Kishiwada, Nara, Sakai, Suita, } \\
\text { Takatsuki, Wakayama, Yao. } \\
\text { R2: Aomori, Iwaki, } \\
\text { Morioka, Sendai. } \\
\text { R3: Atsugi, Funabashi, Hino, } \\
\text { Hitachinaka, Kawaguchi, } \\
\text { Maebashi, Nagareyama, Noda, } \\
\text { Odawara, Oyama, Saitama. }\end{array}$ & $\begin{array}{l}\text { R1: } 86.8 \% \\
\text { R2: } 99.6 \% \\
\text { R3: } 43.3 \%\end{array}$ & 51.6 & 33.9 & $256 \mathrm{M}$ & 165 \\
\hline
\end{tabular}


Table 2. Cont.

\begin{tabular}{|c|c|c|c|c|c|c|}
\hline Problem Data & $\begin{array}{l}\text { Operating Facilities in } R 1, R 2 \text {, } \\
\text { and } R 3\end{array}$ & Coverage \% & MZ & MY & Obj & Time \\
\hline $\begin{array}{c}q_{l}: \mathrm{U}(30,50) \\
c p_{l}: \mathrm{U}(20 \mathrm{k}, 30 \mathrm{k}) \\
f_{i}: \mathrm{U}(70 \mathrm{k}, 90 \mathrm{k}) \\
h_{i}: \mathrm{U}(4 \mathrm{M}, 6 \mathrm{M})\end{array}$ & $\begin{array}{l}\text { R1: Amagasaki, Kakogawa, } \\
\text { Kishiwada, Nara, Sakai, } \\
\text { Suita, Takatsuki. } \\
\text { R2: Aomori, Fukushima, } \\
\text { Hachinohe, Iwaki, Koriyama, } \\
\text { Morioka, Sendai. } \\
\text { R3: Atsugi, Funabashi, Hino, } \\
\text { Hitachinaka, Kawaguchi, } \\
\text { Maebashi, Odawara, } \\
\text { Oyama, Saitama. }\end{array}$ & $\begin{array}{l}\text { R1: } 8.6 \% \\
\text { R2: } 37.5 \% \\
\text { R3: } 4.3 \%\end{array}$ & 50.6 & 39.9 & $22 \mathrm{M}$ & 71 \\
\hline $\begin{array}{c}q_{l}: \mathrm{U}(30,50) \\
c p_{l}: \mathrm{U}(20 \mathrm{k}, 30 \mathrm{k}) \\
f_{i}: \mathrm{U}(100 \mathrm{k}, 150 \mathrm{k}) \\
h_{i}: \mathrm{U}(4 \mathrm{M}, 6 \mathrm{M})\end{array}$ & $\begin{array}{c}\text { R1: Amagasaki, Izumi, } \\
\text { Kakogawa, Kishiwada, Nara, } \\
\text { Sakai, Suita, Takatsuki, } \\
\text { Wakayama, Yao. } \\
\text { R2: Aomori, Iwaki, } \\
\text { Morioka, Sendai. } \\
\text { R3: Atsugi, Funabashi, Hino, } \\
\text { Hitachinaka, Kawaguchi, } \\
\text { Maebashi, Nagareyama, } \\
\text { Odawara, Oyama, Saitama. }\end{array}$ & $\begin{array}{l}\text { R1: } 86.7 \% \\
\text { R2: } 99.6 \% \\
\text { R3: } 43.3 \%\end{array}$ & 51.3 & 33.9 & $250 \mathrm{M}$ & 330 \\
\hline $\begin{array}{c}q_{l}: \mathrm{U}(30,50) \\
c p_{l}: \mathrm{U}(20 \mathrm{k}, 30 \mathrm{k}) \\
f_{i}: \mathrm{U}(100 \mathrm{k}, 150 \mathrm{k}) \\
h_{i}: \mathrm{U}(4 \mathrm{M}, 6 \mathrm{M})\end{array}$ & $\begin{array}{c}\text { R1: Akashi, Amagasaki, } \\
\text { Higashiosaka, Himeji, } \\
\text { Hirakata, Ibaraki, Itami, Izumi, } \\
\text { Kakogawa, Kawanishi, } \\
\text { Kishiwada, Kobe, Kyoto, Nara, } \\
\text { Neyagawa, Nishinomiya, } \\
\text { Okayama, Osaka, Otsu, Sakai, } \\
\text { Suita, Takarazuka, Takatsuki, } \\
\text { Toyonaka, Uji, Wakayama, Yao. } \\
\text { R2: Aomori, Fukushima, } \\
\text { Hachinohe, Iwaki, Koriyama, } \\
\text { Morioka, Sendai. } \\
\text { R3: Ageo, Atsugi, Chiba, } \\
\text { Chigasaki, Chofu, Fucho, } \\
\text { Fujisawa, Funabashi, Hachioji, } \\
\text { Hino, Hiratsuka, Hitachinaka, } \\
\text { Ichihara, Ichikawa, Isesaki, } \\
\text { Kamakura, Kashiwa, Kasukabe, } \\
\text { Kawagoe, Kawaguchi, } \\
\text { Kawasaki, Kodaira, Koshigaya, } \\
\text { Kuki, Kumagaya, Machida, } \\
\text { Maebashi, Matsudo, Mitaka, } \\
\text { Mito, Nagareyama, Narashino, } \\
\text { Niiza, Nishitokyo, Noda, } \\
\text { Odawara, Ota, Oyama, } \\
\text { Sagamihara, Saitama, Sakura, } \\
\text { Sayama, Soka, Tachikawa, } \\
\text { Takasaki,Tochigi, } \\
\text { Tokyo,Tsukuba, Urayasu, } \\
\text { Utsunomiya,Yachiyo. }\end{array}$ & $\begin{array}{l}\text { R1: } 39.5 \% \\
\text { R2: } 47.6 \% \\
\text { R3: } 33.9 \%\end{array}$ & 93 & 35.1 & $140 \mathrm{M}$ & 1046 \\
\hline
\end{tabular}


The second column of Table 2 shows the operating facilities in each strategic period for R1, R2, and R3. The columns "MZ" and "MY" contain the average number of located facilities and modules, respectively. Columns "Obj" and "Time" include the objective value and elapsed time to solve the problem. Other rows of Table 2 contain the results for some sensitivity analysis of capacity and cost parameters. In the second solved problem, the capacities of the modules decreased, which resulted in a significant coverage percentage for all regions and objective values. The number of located facilities does not change so much, but the problem tries to provide more coverage by assigning more modules. In the third problem, the effect of increasing the facility location cost was the main purpose. The results show that the increase in facility location cost does not have that much effect on the coverage percentage and assigned modules but the number of located facilities, and as a result, the objective value decreases. In addition, the last solved problem investigates the effect of the decrease in facilities capacity. According to the results, when the capacity of facilities decreases, more facilities are located, but even this increase in the number of facilities cannot compensate for the reduction in the coverage percentage. On the other hand, locating more facilities imposes costs, which is reflected in the objective value reduction.

\subsection{Numerical Results}

In this section, some test problems were generated randomly with different sizes to examine the performance of the developed HCLP model. For this purpose, the test problems were designed in two main directions. In the first experiment, it is supposed that there are three regions affected by disasters with two kinds of high and low demand scenarios in three strategic periods. In the second experiment, there are four regions affected by the disasters with high and low demand scenarios in four strategic periods. A schematic illustration of three regions and four regions test problems together with the located facilities, and the module movement flow is depicted in Figure 5 for the case with 250 demand points. In each kind of experiment, the dimensions of the test problems are augmented gradually. Tables 3 and 4 contain the results of the test problems. The problems are solved using Generic Algebraic Modelling System (GAMS) (CPLEX solver) software (24.1.2) on a PC with a 3.4-GHz Core i7-6700 CPU and 8 GB of RAM running Windows 10 (64 bit). It must be noted that all parameters of the test problems are designed in a way that there would be no redundant constraints. The results for all test problems approve that problems of low scenarios result in less objective values, but a higher percentage of demands can be covered in the low scenario problems compared to the high demand scenario problems. By increasing the size of the problems, the elapsed time also increases for both kinds of problems in Tables 3 and 4. For the problem of the size 250 points of three regions, we conducted some sensitivity analyses. As mentioned, the first two problems of low and high demands are the problems that all the constraints are active. By increasing the capacity of facilities, in second and third problems, the constraints of the facilities capacity become redundant, so that changing these parameters has no more effect on the solutions. In the last problem, the capacities of the facilities are set to be active, and the capacities of the modules are increased such that these changes yield to increase in objective value and coverage percentage, though the difference is not much significant. Comparing the results of the coverage percentage for two tables, it becomes clear that, for large-scale problems, the problems of four regions could provide significantly better coverage. The reason for the difference in parameter values in two kinds of problems (Tables 3 and 4 ) is to avoid having redundant constraints. GAMS was able to solve the problems of 250 demand points. However, this size of the problem is not regarded as a small size, because considering the modules and sizes and two kinds of time periods, the real size of the problems are in the category of large-size problems. 

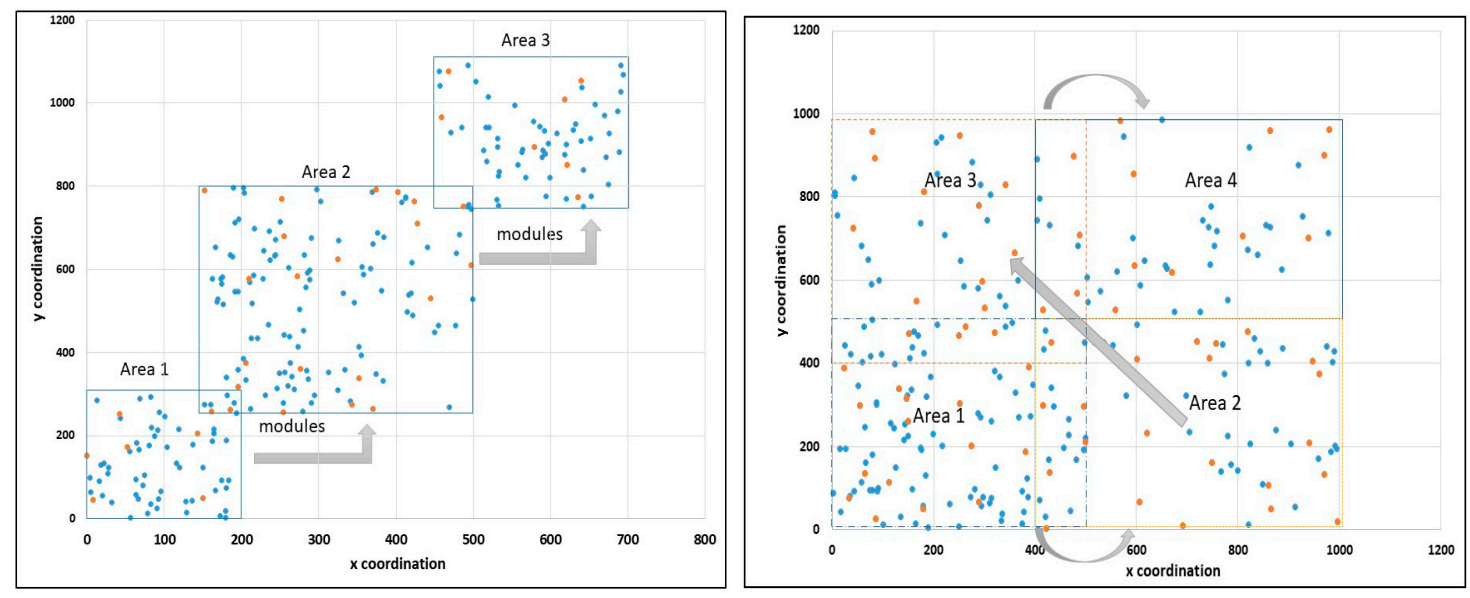

Figure 5. A schematic illustration of three-region and four-region test problems.

Table 3. Computational results of test problems for three regions' experiments.

\begin{tabular}{ccccccccccccc}
\hline \multirow{2}{*}{$\boldsymbol{i = j}$} & $\begin{array}{c}\text { Demand } \\
\text { Scenario }\end{array}$ & $\boldsymbol{t}$ & $\boldsymbol{\tau}$ & $\boldsymbol{l}$ & $\boldsymbol{k}$ & $\boldsymbol{q}_{\boldsymbol{l}}$ & $\boldsymbol{c} \boldsymbol{p}_{\boldsymbol{l}}$ & $\boldsymbol{h}_{\boldsymbol{i}}$ & $\boldsymbol{f}_{\boldsymbol{i}}$ & Obj & Coverage \% & Time \\
\hline \multirow{2}{*}{50} & Low & 3 & 2 & 2 & 2 & $\mathrm{U}(4,7)$ & $\mathrm{U}(150,250)$ & $\mathrm{U}(500,1000)$ & $\mathrm{U}(400,800)$ & 3042.1 & $86 \%$ & 4 \\
& High & 3 & 2 & 2 & 2 & $\mathrm{U}(4,7)$ & $\mathrm{U}(150,250)$ & $\mathrm{U}(500,1000)$ & $\mathrm{U}(400,800)$ & 4359.5 & $65 \%$ & 3 \\
\hline \multirow{2}{*}{100} & Low & 3 & 3 & 2 & 3 & $\mathrm{U}(7,10)$ & $\mathrm{U}(200,250)$ & $\mathrm{U}(1000,1500)$ & $\mathrm{U}(400,800)$ & $17,251.2$ & $84 \%$ & 213 \\
& High & 3 & 3 & 2 & 3 & $\mathrm{U}(7,10)$ & $\mathrm{U}(200,250)$ & $\mathrm{U}(1000,1500)$ & $\mathrm{U}(400,800)$ & $21,936.2$ & $62 \%$ & 249 \\
\hline \multirow{2}{*}{150} & Low & 3 & 3 & 3 & 3 & $\mathrm{U}(10,15)$ & $\mathrm{U}(200,250)$ & $\mathrm{U}(1500,2000)$ & $\mathrm{U}(400,800)$ & $41,056.5$ & $86 \%$ & 1013 \\
& High & 3 & 3 & 3 & 3 & $\mathrm{U}(10,15)$ & $\mathrm{U}(200,250)$ & $\mathrm{U}(1500,2000)$ & $\mathrm{U}(400,800)$ & $50,697.4$ & $62 \%$ & 1073 \\
\hline \multirow{2}{*}{200} & Low & 3 & 3 & 4 & 3 & $\mathrm{U}(15,20)$ & $\mathrm{U}(300,350)$ & $\mathrm{U}(1000,1500)$ & $\mathrm{U}(400,800)$ & $25,134.5$ & $30 \%$ & 1029 \\
& High & 3 & 3 & 4 & 3 & $\mathrm{U}(15,20)$ & $\mathrm{U}(300,350)$ & $\mathrm{U}(1000,1500)$ & $\mathrm{U}(400,800)$ & 26,740 & $22 \%$ & 1072 \\
\hline \multirow{6}{*}{250} & Low & 3 & 4 & 4 & 3 & $\mathrm{U}(20,30)$ & $\mathrm{U}(300,350)$ & $\mathrm{U}(1000,1500)$ & $\mathrm{U}(400,800)$ & $24,545.6$ & $21.9 \%$ & 2169 \\
& High & 3 & 4 & 4 & 3 & $\mathrm{U}(20,30)$ & $\mathrm{U}(300,350)$ & $\mathrm{U}(1000,1500)$ & $\mathrm{U}(400,800)$ & $27,159.4$ & $14.1 \%$ & 1479 \\
& Low & 3 & 4 & 4 & 3 & $\mathrm{U}(20,30)$ & $\mathrm{U}(300,350)$ & $\mathrm{U}(1500,2000)$ & $\mathrm{U}(400,800)$ & 28,235 & $24 \%$ & 1203 \\
& High & 3 & 4 & 4 & 3 & $\mathrm{U}(20,30)$ & $\mathrm{U}(300,350)$ & $\mathrm{U}(1500,2000)$ & $\mathrm{U}(400,800)$ & $31,482.5$ & $16 \%$ & 1355 \\
& Low & 3 & 4 & 4 & 3 & $\mathrm{U}(20,30)$ & $\mathrm{U}(300,350)$ & $\mathrm{U}(2000,3000)$ & $\mathrm{U}(400,800)$ & 28,235 & $24 \%$ & 1169 \\
& High & 3 & 4 & 4 & 3 & $\mathrm{U}(20,30)$ & $\mathrm{U}(300,350)$ & $\mathrm{U}(2000,3000)$ & $\mathrm{U}(400,800)$ & $31,482.5$ & $16 \%$ & 1399 \\
& Low & 3 & 4 & 4 & 3 & $\mathrm{U}(20,30)$ & $\mathrm{U}(350,450)$ & $\mathrm{U}(1000,1500)$ & $\mathrm{U}(400,800)$ & $25,744.6$ & $22.6 \%$ & 1343 \\
& High & 3 & 4 & 4 & 3 & $\mathrm{U}(20,30)$ & $\mathrm{U}(350,450)$ & $\mathrm{U}(1000,1500)$ & $\mathrm{U}(400,800)$ & 28,396 & $14.6 \%$ & 1111 \\
\hline
\end{tabular}

Table 4. Computational results of test problems for four regions' experiments.

\begin{tabular}{|c|c|c|c|c|c|c|c|c|c|c|c|c|}
\hline$i=j$ & $\begin{array}{l}\text { Demand } \\
\text { Scenario }\end{array}$ & $t$ & $\tau$ & $l$ & $k$ & $q_{l}$ & $c p_{l}$ & $h_{i}$ & $f_{i}$ & Obj & Coverage $\%$ & Time \\
\hline \multirow{2}{*}{50} & Low & 4 & 2 & 2 & 2 & $\mathrm{U}(4,7)$ & $\mathrm{U}(150,250)$ & $\mathrm{U}(400,800)$ & $\mathrm{U}(400,800)$ & 715.1 & $82 \%$ & 6 \\
\hline & High & 4 & 2 & 2 & 2 & $\mathrm{U}(4,7)$ & $\mathrm{U}(150,250)$ & $\mathrm{U}(400,800)$ & $\mathrm{U}(400,800)$ & 2660.9 & $76 \%$ & 5 \\
\hline \multirow{2}{*}{100} & Low & 4 & 3 & 2 & 3 & $\mathrm{U}(7,10)$ & $\mathrm{U}(200,250)$ & $\mathrm{U}(1000,1500)$ & $\mathrm{U}(400,800)$ & $13,751.9$ & $68 \%$ & 82 \\
\hline & High & 4 & 3 & 2 & 3 & $\mathrm{U}(7,10)$ & $\mathrm{U}(200,250)$ & $\mathrm{U}(1000,1500)$ & $\mathrm{U}(400,800)$ & $18,627.9$ & $62 \%$ & 126 \\
\hline \multirow{2}{*}{150} & Low & 4 & 3 & 3 & 3 & $\mathrm{U}(10,15)$ & $\mathrm{U}(200,250)$ & $\mathrm{U}(1500,2000)$ & $\mathrm{U}(400,800)$ & $49,496.5$ & $83 \%$ & 499 \\
\hline & High & 4 & 3 & 3 & 3 & $\mathrm{U}(10,15)$ & $\mathrm{U}(200,250)$ & $\mathrm{U}(1500,2000)$ & $\mathrm{U}(400,800)$ & $60,916.8$ & $76 \%$ & 672 \\
\hline \multirow{2}{*}{200} & Low & 4 & 3 & 4 & 3 & $\mathrm{U}(15,20)$ & $\mathrm{U}(200,250)$ & $\mathrm{U}(1500,2000)$ & $\mathrm{U}(400,800)$ & $66,291.6$ & $55 \%$ & 1083 \\
\hline & High & 4 & 3 & 4 & 3 & $\mathrm{U}(15,20)$ & $\mathrm{U}(200,250)$ & $\mathrm{U}(1500,2000)$ & $\mathrm{U}(400,800)$ & $77,956.4$ & $46 \%$ & 1076 \\
\hline \multirow{2}{*}{250} & Low & 4 & 4 & 4 & 3 & $\mathrm{U}(20,30)$ & $\mathrm{U}(300,450)$ & $\mathrm{U}(1500,2000)$ & $\mathrm{U}(400,800)$ & $63,323.5$ & $52 \%$ & 1115 \\
\hline & High & 4 & 4 & 4 & 3 & $\mathrm{U}(20,30)$ & $\mathrm{U}(300,450)$ & $\mathrm{U}(1500,2000)$ & $\mathrm{U}(400,800)$ & 76,925 & $43 \%$ & 1757 \\
\hline
\end{tabular}

\subsection{Model Validation and Comparison Results}

To validate the developed model, two approaches are deployed. In the first approach, the solutions of hybrid covering location problem will be compared with the results of the conventional separate models for some of the test problems from Table 3. In order to do this, we compare the results of HCLP with the problem in which the location of the facilities would be selected by SCLP separately using the second term of the objective function (6) (minimizing the cost of facility location) subject to constraints (7), (8), (11), and (14). The solutions of the located facilities are used and fixed in the second problem to 
assign the modules and allocate the demand points using the first term of the objective function (6) (maximizing the total covered demands) subject to constraints (9)-(13).

The computational results are illustrated in Table 5, in which the columns under "Hybrid" and "Con." include the results of the hybrid covering location problem and the described conventional procedure, respectively. Rows of "Obj" show the objective value of income minus fixed cost of facility locations for both methods. Furthermore, the last row of Table 5 shows the results for the total number of the assigned modules in all time periods out of the predefined amounts of available modules. For example, the value 58/66 means that the problem used 58 modules out of 66 available modules. The higher is this proportion, the problem used the available resources in a better way. The results of this conducted comparison show that using the integrated location decisions of SCLP and MCLP in a united model can improve the objective value, and this fact can be interpreted as the quality of provided services. It is important to note that the less value of facility cost in the conventional approach cannot be an advantage, as far as the total objective value is not better than hybrid approach, and these values are calculated and included in the table to have the evaluation of cost differences in both approaches. The results of Table 5 make it apparent that the hybrid approach has significant superiority to the conventional approach regarding objective value, coverage percentage, and exploiting the available modules.

Table 5. Computational results for comparing the performances of hybrid and conventional approaches. The bold is necessary as it shows the performance of the better method.

\begin{tabular}{ccccccccc}
\hline & \multicolumn{2}{c}{$\mathbf{5 0}$ High } & \multicolumn{2}{c}{$\mathbf{1 0 0}$ High } & \multicolumn{2}{c}{$\mathbf{1 5 0}$ High } & \multicolumn{2}{c}{$\mathbf{2 0 0}$ High } \\
\cline { 2 - 9 } & Hybrid & Con. & Hybrid & Con. & Hybrid & Con. & Hybrid & Con. \\
\hline Obj & $\mathbf{4 3 5 9}$ & 1276 & $\mathbf{2 1 , 9 3 6}$ & 10,956 & $\mathbf{5 0 , 6 9 7}$ & 10,126 & $\mathbf{2 6 , 7 4 0}$ & 9689 \\
Facility cost & 5258 & 2470 & 5025 & 2559 & 11,230 & 2470 & 11,712 & 2409 \\
Coverage $\%$ & $\mathbf{6 5 . 7 \%}$ & $25.6 \%$ & $\mathbf{6 1 . 9} \%$ & $31 \%$ & $\mathbf{6 2} \%$ & $12.8 \%$ & $\mathbf{2 2 \%}$ & $0.7 \%$ \\
Total modules & $\mathbf{5 8 / 6 6}$ & $28 / 66$ & $\mathbf{1 2 0 / 1 2 6}$ & $72 / 126$ & $\mathbf{3 0 4 / 3 0 6}$ & $108 / 306$ & $\mathbf{2 1 6 / 6 2 1}$ & $144 / 621$ \\
\hline
\end{tabular}

The same problems of the previous section in Tables 3 and 4 are solved for problems MCLP-MCLP, MCLP-SCLP, and SCLP-SCLP. It is important to note that we have first solved HCLP and obtained the total number of facilities that is determined to be opened and then used these numbers and run the experiments for the problems that need to have the number of facilities to be located, i.e., MCLP-MCLP and MCLP-SCLP.

To be able to compare the models, two criteria were investigated. The first one that is in alignment with the optimization criteria as equity or fairness [58] that we interpret here as the percentage of coverage provided for demand points calculated as the total amount of covered demand divided by the total amount of demands, as explained earlier. The next investigated optimization criterion is the efficiency of models as the elapsed time to obtain the results.

The columns under " $Z$ " and " $Y$ " contain the average number of facilities in all strategic periods and the average number of the assigned modules in all tactical periods, respectively. Tables 6 and 7 contain the results of these evaluations. To complete the tables and solve the problems of MCLP-MCLP and MCLP-SCLP, there was needed to have the number of facilities to be located. For this purpose, firstly, the problem HCLP was solved, and its solutions of the located facilities in the last strategic period $(|T|)$ were used in MCLP-MCLP and MCLP-SCLP with two different values: one with the higher number (to provide even more facilities) and the other one with the optimal solution of HCLP. Solving problems for the values of $p_{|T|}$ smaller than the values in Tables 6 and 7 would not result in better solutions. According to the results of the coverage percentage for HCLP, MCLP-MCLP, and MCLP-SCLP, HCLP could provide the highest coverage percentage almost for all test problems, with an optimum number of facilities. Only in three cases with the number of facilities more than the optimal number, the coverage percentage was better (one case of MCLP-MCLP and two cases of MCLP-SCLP). Notice that we excluded SCLP-SCLP from these comparisons, because we believe that 
the solution, which sets all the demand points to be a facility, is not a practical solution. Among the three variants of MCLP-MCLP, MCLP-SCLP, and SCLP-SCLP, it was expected that SCLP-SCLP can provide the best coverage, as it does not have any budgetary limitations. However, the results show that this problem has a good performance neither for coverage nor the number of located facilities and modules. The problem MCLP-SCLP has good performance for the only one size problem that it could solve, and for the rest of the problems, it was either infeasible or no solution was found by the solver. Among all three variants, MCLP-MCLP is the only problem that was successful in obtaining solutions. Although the coverage percentage is not better than HCLP, it has an overall acceptable performance. However, this problem was not able to solve larger problems, and the general-purpose solver required higher computational effort. Concerning the optimization criteria mentioned above, the results obtained from test problems show that, in terms of both equity (coverage percentage) and efficiency (elapsed time), the problem HCLP outperforms other variants and can provide better coverage in a reasonable time for different size of test problems.

Table 6. Computational results to compare different variants for three regions. HCLP: hybrid covering location problem.

\begin{tabular}{|c|c|c|c|c|c|c|c|c|c|c|c|c|c|c|c|c|c|c|}
\hline \multirow{2}{*}{$i=j$} & \multirow{2}{*}{$\begin{array}{l}\text { Demand } \\
\text { Scenario }\end{array}$} & \multirow{2}{*}{$p_{|T|}$} & \multicolumn{4}{|c|}{ HCLP } & \multicolumn{4}{|c|}{ MCLP-MCLP } & \multicolumn{4}{|c|}{ MCLP-SCLP } & \multicolumn{4}{|c|}{ SCLP-SCLP } \\
\hline & & & $\%$ & $\mathbf{Z}$ & $\mathbf{Y}$ & $\mathrm{T}$ & $\%$ & $\mathbf{Z}$ & $\mathbf{Y}$ & $\mathbf{T}$ & $\%$ & $\mathbf{Z}$ & $\mathbf{Y}$ & $\mathbf{T}$ & $\%$ & $\mathrm{Z}$ & $\mathbf{Y}$ & $\mathrm{T}$ \\
\hline \multirow{4}{*}{50} & \multirow{2}{*}{ Low } & 3 & 86 & 3.3 & 4.3 & 6 & 79 & 3 & 3.8 & 2 & 82 & 3 & 5.5 & 4 & 0 & 3 & 4.6 & 0.8 \\
\hline & & 4 & - & - & - & - & 89 & 3.3 & 4.2 & 7 & 91 & 4 & 6 & 11 & & & & \\
\hline & \multirow{2}{*}{ High } & 3 & 65 & 3.6 & 4.3 & 2 & 53 & 3 & 3.8 & 2 & 59 & 3 & 5.6 & 2 & 0 & 3 & 4.2 & 0.7 \\
\hline & & 4 & - & - & - & - & 61 & 3.3 & 4.3 & 4 & 74 & 4 & 7 & 11 & & & & \\
\hline \multirow{4}{*}{100} & \multirow{2}{*}{ Low } & 3 & 84 & 3.6 & 6.5 & 213 & 75 & 3 & 5.3 & 219 & \multirow{2}{*}{\multicolumn{4}{|c|}{$\begin{array}{l}\text { Inf } \\
\text { Inf }\end{array}$}} & 41 & 100 & 197 & 1006 \\
\hline & & 4 & - & - & - & - & 82 & 4 & 6 & 904 & & & & & & & & \\
\hline & \multirow{2}{*}{ High } & 3 & 62 & 3.6 & 6.6 & 255 & 50 & 3 & 5.3 & 268 & \multicolumn{4}{|c|}{ Inf } & 42 & 100 & 197 & 1006 \\
\hline & & 4 & - & - & - & - & 59 & 4 & 6.3 & 180 & \multicolumn{4}{|c|}{ Inf } & - & - & - & - \\
\hline \multirow{2}{*}{150} & Low & 8 & 86 & 8 & 10.7 & 10,013 & \multicolumn{4}{|c|}{$\mathrm{RE}$} & \multicolumn{4}{|c|}{ NS } & 39 & 150 & 301 & 1015 \\
\hline & High & 7 & 62 & 7.6 & 11.2 & 10,473 & \multicolumn{4}{|c|}{$\mathrm{RE}$} & \multicolumn{4}{|c|}{ NS } & 40 & 150 & 301 & 1019 \\
\hline \multirow{2}{*}{200} & Low & 7 & 30 & 7 & 6 & 1064 & \multirow{2}{*}{\multicolumn{4}{|c|}{$\begin{array}{l}\text { RE } \\
\text { RE }\end{array}$}} & \multirow{2}{*}{\multicolumn{4}{|c|}{$\begin{array}{l}\text { NS } \\
\text { NS }\end{array}$}} & 44 & 200 & 399 & 1051 \\
\hline & High & 7 & 22 & 7 & 6 & 1050 & & & & & & & & & 44 & 200 & 399 & 1052 \\
\hline \multirow{2}{*}{250} & Low & 22 & 22 & 22 & 5.3 & 1583 & \multirow{2}{*}{\multicolumn{4}{|c|}{$\begin{array}{l}\text { RE } \\
\text { RE }\end{array}$}} & \multirow{2}{*}{\multicolumn{4}{|c|}{$\begin{array}{l}\text { NS } \\
\text { NS }\end{array}$}} & 40 & 250 & 499 & 1094 \\
\hline & High & 22 & 14 & 22 & 5.3 & 1505 & & & & & & & & & 40 & 250 & 499 & 1103 \\
\hline
\end{tabular}

Table 7. Computational results to compare different variants for four regions.

\begin{tabular}{|c|c|c|c|c|c|c|c|c|c|c|c|c|c|c|c|c|c|c|}
\hline \multirow{2}{*}{$i=j$} & \multirow{2}{*}{$\begin{array}{l}\text { Demand } \\
\text { Scenario }\end{array}$} & \multirow{2}{*}{$p_{|T|}$} & \multicolumn{4}{|c|}{ HCLP } & \multicolumn{4}{|c|}{ MCLP-MCLP } & \multicolumn{4}{|c|}{ MCLP-SCLP } & \multicolumn{4}{|c|}{ SCLP-SCLP } \\
\hline & & & $\%$ & $\mathrm{Z}$ & $\mathbf{Y}$ & $\mathrm{T}$ & $\%$ & $\mathbf{Z}$ & $\mathbf{Y}$ & $T$ & $\%$ & $\mathbf{Z}$ & $\mathbf{Y}$ & $\mathbf{T}$ & $\%$ & $\mathbf{Z}$ & Y & $\mathrm{T}$ \\
\hline \multirow{4}{*}{50} & \multirow{2}{*}{ Low } & 4 & 82 & 4.5 & 5.2 & 6 & 82 & 3.5 & 4.7 & 10 & \multicolumn{4}{|c|}{ NS } & 0 & 5 & 7.5 & 1 \\
\hline & & 5 & - & - & - & - & 89 & 4.5 & 5 & 8 & 76 & 5 & 8.1 & 3 & - & - & - & - \\
\hline & \multirow{2}{*}{ High } & 4 & 76 & 4.5 & 5.5 & 3 & 76 & 3.5 & 5.4 & 10 & \multicolumn{4}{|c|}{ NS } & 0 & 5 & 7.25 & 2 \\
\hline & & 5 & - & - & - & - & 82 & 4.5 & 5 & 11 & 70 & 5 & 8.5 & 3 & - & - & - & - \\
\hline \multirow{4}{*}{100} & \multirow{2}{*}{ Low } & 5 & 68 & 5.5 & 6.3 & 84 & 63 & 3.7 & 5.2 & 98 & 25 & 5 & 11.4 & 397 & 21 & 6 & 12.9 & 292 \\
\hline & & 6 & - & - & - & - & 68 & 4.5 & 6.3 & 100 & 27 & 6 & 11 & 584 & - & - & - & - \\
\hline & \multirow{2}{*}{ High } & 5 & 62 & 5.7 & 6.5 & 53 & 61 & 4.2 & 6.6 & 45 & \multirow{2}{*}{\multicolumn{4}{|c|}{$\begin{array}{l}\text { NS } \\
\text { NS }\end{array}$}} & 30 & 7 & 15.8 & 485 \\
\hline & & 6 & - & - & - & - & 60 & 4.2 & 6.1 & 32 & & & & & - & - & - & - \\
\hline \multirow{4}{*}{150} & \multirow{2}{*}{ Low } & 7 & 83 & 7.5 & 10 & 499 & 76 & 5.7 & 8.5 & 1020 & \multirow{2}{*}{\multicolumn{4}{|c|}{ NS }} & 28 & 21.7 & 26.4 & 1023 \\
\hline & & 8 & - & - & - & - & 72 & 4.7 & 8.1 & 1015 & & & & & - & - & - & - \\
\hline & \multirow{2}{*}{ High } & 7 & 76 & 8 & 10.1 & 672 & 62 & 4.7 & 8.5 & 1025 & \multicolumn{4}{|c|}{ NS } & 28 & 150 & 301 & 1029 \\
\hline & & 8 & - & - & - & - & 48 & 3.7 & 6.3 & 1022 & 22 & 8 & 24 & 1020 & - & - & - & - \\
\hline \multirow{2}{*}{200} & Low & 14 & 55 & 14 & 11.6 & 1083 & \multirow{2}{*}{\multicolumn{4}{|c|}{$\begin{array}{l}\text { RE } \\
\text { RE }\end{array}$}} & \multirow{2}{*}{\multicolumn{4}{|c|}{$\begin{array}{l}\text { NS } \\
\text { NS }\end{array}$}} & 30 & 200 & 399 & 1062 \\
\hline & High & 14 & 46 & 14 & 11.7 & 1076 & & & & & & & & & 31 & 200 & 399 & 1094 \\
\hline \multirow{2}{*}{250} & Low & 21 & 52 & 21.7 & 15.1 & 1115 & \multirow{2}{*}{\multicolumn{4}{|c|}{$\begin{array}{l}\text { RE } \\
\text { RE }\end{array}$}} & \multirow{2}{*}{\multicolumn{4}{|c|}{$\begin{array}{l}\text { NS } \\
\text { NS }\end{array}$}} & 27 & 250 & 500 & 1131 \\
\hline & High & 21 & 43 & 21.7 & 15.1 & 1757 & & & & & & & & & \multicolumn{4}{|c|}{ RE } \\
\hline
\end{tabular}

RE: resource exceeded and NS: no solution. 
The number of variables is the same in all variant problems, but the number of constraints is different, which has an influence on the efficiency of the results. As the Constraints of (8)-(11), (13)-(15), and (19) are the same in all problems, we name this set of constraints $\Delta$, and our comparison takes into account the rest of the constraints in each problem. The number of constraints and an example of the problem with 50 demand points studied as the first problem in Table 3 is included in Table 8. In our test problems, the number of modules and strategic and tactical periods do not take large values, but it is the number of demand points that has a considerable impact by augmenting the size of problems. Therefore, it can be concluded that SCLP-SCLP has the largest number of constraints, and the order after SCLP-SCLP is MCLP-SCLP, HCLP, and MCLP-MCLP. However, the computational times of problems and the fact that MCLP-MCLP/MCLP-SCLP exceeded resources/no solution results for most of the test problems, the difference in the number of constraints does not have a significant impact on the quality of the results or computational time.

Table 8. Comparing total number of constraints in HCLP, MCLP-MCLP, MCLP-SCLP, and SCLP-SCLP.

\begin{tabular}{cll}
\hline Problem & Number of Constraints & \multicolumn{1}{c}{ Example } \\
\hline HCLP & $\Delta+\left|J\|T|+| L\| T \| \mathcal{T}_{t}\right|$ & $\Delta+50 \times 3+2 \times 3 \times 2=\Delta+162$ \\
MCLP-MCLP & $\Delta+|T|+\left|L\|T\| \mathcal{T}_{t}\right|$ & $\Delta+3+2 \times 3 \times 2=\Delta+15$ \\
MCLP-SCLP & $\Delta+|T|+\left|J\|L\| T \| \mathcal{T}_{t}\right|$ & $\Delta+3+50 \times 2 \times 3 \times 2=\Delta+603$ \\
SCLP-SCLP & $\Delta+|J\|T|+| J|| L\| T|\left|\mathcal{T}_{t}\right|$ & $\Delta+50 \times 3+50 \times 2 \times 3 \times 2=\Delta+750$ \\
\hline
\end{tabular}

\section{Conclusions}

To address the facility location problem in a disaster relief situation, a novel model combining the advantages of two major covering location problems was developed in this paper. The coverage concept of two major covering location problems: set covering location problem and maximal covering location problem was utilized to develop the model of the hybrid covering location problem. In the developed HCLP, the location of the facilities was determined by using SCLP, and the limited number of modules providing different services can be assigned to the facilities to provide services in tactical periods. To investigate the capability of the developed hybrid covering location problem, an application for it was introduced as locating aid centers in humanitarian relief services. A case study using real data for demand points in Japan was used, together with some more randomly generated test problems. The results of the studied problems showed that the developed mathematical model can obtain accurate solutions compatible with the real situations and the assumptions of the model.

Furthermore, the other possible combinations of covering location problems were developed as the variants of the main hybrid covering location problem. To evaluate the four developed models, some test problems were generated and solved for all variants. The computational results approve that the main developed hybrid model of this paper can outperform the other three variants in terms of coverage percentage, solution quality, and feasibility of the solutions.

One important fact about the developed hybrid covering location problem in this paper is that it can be solved with commercial solver (GAMS) for problems of an acceptable size of real-life situations, which is an important specification for problems arising in disaster situations that need quick responses. However, in most of the problems studied with other researches, the difficulty in solving the problems to obtain the solutions is a barrier to be applicable in disaster situations. The main purpose of this paper was to introduce the basic and original framework of the hybrid covering location problem, while the problem developed in this paper can be used to be coupled with other decisions of the supply chain, such as inventory management and vehicle routing. In addition, it can be studied as a two-stage or multi-stage stochastic programming model that can be a future direction for research.

Author Contributions: Conceptualization, R.A. and T.N.; Data curation, R.A.; Formal analysis, R.A.; Funding acquisition, T.N.; Investigation, R.A. and T.N.; Methodology, R.A.; Project administration, T.N.; Supervision, T.N.; Validation, R.A.; Visualization, R.A.; Writing—original draft, R.A.; Writing—review \& editing, T.N. All authors have read and agreed to the published version of the manuscript. 
Funding: This research was conducted by the aid of funding provided by JSPS KAKENHI(A) 18 H03826.

Conflicts of Interest: The authors declare no conflict of interest.

\section{References}

1. Farahani, R.Z.; Asgari, N.; Heidari, N.; Hosseininia, M.; Goh, M. Covering problems in facility location: A review. Comput. Ind. Eng. 2012, 62, 368-407. [CrossRef]

2. Fazel Zarandi, M.H.; Davari, S.; Haddad Sisakht, S.A. The large scale maximal covering location problem. Sci. Iran. 2011, 18, 1564-1570. [CrossRef]

3. Laporte, G.; Nickel, S.; Saldanha-da-Gama, F. Introduction to location science. In Location Science; Springer: Cham, Switzerland, 2019; pp. 1-18.

4. Berman, O.; Drezner, Z.; Krass, D. Generalized coverage: New developments in covering location models. Comput. Oper. Res. 2010, 37, 1675-1687. [CrossRef]

5. Li, X.; Zhao, Z.; Zhu, X.; Wyatt, T. Covering models and optimization techniques for emergency response facility location and planning: A review. Math. Methods Oper. Res. 2011, 74, 281-310. [CrossRef]

6. Zarandi, M.H.F.; Davari, S.; Sisakht, S.A.H. The large-scale dynamic maximal covering location problem. Math. Comput. Model. 2013, 57,710-719. [CrossRef]

7. Youshanlo, M.F.; Sahraeian, R. Dynamic Multi-Objective Maximal Vovering Location Problem with Gradual Coverage. Enhancing Synergies in a Collaborative Environment; Springer: Cham, Switzerland, 2015; pp. 39-47.

8. Vatsa, A.K.; Jayaswal, S. Capacitated multi-period maximal covering location problem with server uncertainty. Eur. J. Oper. Res. 2020. [CrossRef]

9. Rajagopalan, H.K.; Saydam, C.; Xiao, J. A multiperiod set covering location model for dynamic redeployment of ambulances. Comput. Oper. Res. 2008, 35, 814-826. [CrossRef]

10. Şahin, G.; Süral, H. A review of hierarchical facility location models. Comput. Oper. Res. 2007, 34, $2310-2331$. [CrossRef]

11. Marianov, V.; Serra, D. Hierarchical location-allocation models for congested systems. Eur. J. Oper. Res. 2001, 135, 195-208. [CrossRef]

12. Correia, I.; Melo, T. A multi-period facility location problem with modular capacity adjustments and flexible demand fulfillment. Comput. Ind. Eng. 2017, 110, 307-321. [CrossRef]

13. Mikić, M.; Todosijević, R.; Urošević, D. Less is more: General variable neighborhood search for the capacitated modular hub location problem. Comput. Oper. Res. 2019, 110, 101-115. [CrossRef]

14. Melo, M.T.; Nickel, S.; Saldanha-da-Gama, F. Facility location and supply chain management-A review. Eur. J. Oper. Res. 2009, 196, 401-412. [CrossRef]

15. Bashiri, M.; Badri, H.; Talebi, J. A new approach to tactical and strategic planning in production-distribution networks. Appl. Math. Model. 2012, 36, 1703-1717. [CrossRef]

16. Moreno, A.; Alem, D.; Ferreira, D.; Clark, A. An effective two-stage stochastic multi-trip locationtransportation model with social concerns in relief supply chains. Eur. J. Oper. Res. 2018, 269, 1050-1071. [CrossRef]

17. Zhang, G.; Nishi, T.; Turner, S.D.O.; Oga, K.; Li, X. An integrated strategy for a production planning and warehouse layout problem: Modeling and solution approaches. Omega 2017, 68, 85-94. [CrossRef]

18. Toregas, C.; Swain, R.; ReVelle, C.; Bergman, L. The location of emergency service facilities. Oper. Res. 1971, 19, 1363-1373. [CrossRef]

19. Murray, A.T.; Wei, R. A computational approach for eliminating error in the solution of the location set covering problem. Eur. J. Oper. Res. 2013, 224, 52-64. [CrossRef]

20. Borrás, F.; Pastor, J.T. The ex-post evaluation of the minimum local reliability level: An enhanced probabilistic location set covering model. Ann. Oper. Res. 2002, 111, 51-74. [CrossRef]

21. Saxena, A.; Goyal, V.; Lejeune, M.A. MIP reformulations of the probabilistic set covering problem. Math. Program. 2010, 121, 1-31. [CrossRef]

22. Vianna, S.S.V. The set covering problem applied to optimisation of gas detectors in chemical process plants. Comput. Chem. Eng. 2019, 121, 388-395. [CrossRef]

23. Vieira, B.S.; Ferrari, T.; Ribeiro, G.M.; Bahiense, L.; Filho, R.D.O.; Abramides, C.A.; Campos Júnior, N.F.R. A progressive hybrid set covering based algorithm for the traffic counting location problem. Expert Syst. Appl. 2020, 160, 113641. [CrossRef] 
24. Park, Y.; Nielsen, P.; Moon, I. Unmanned aerial vehicle set covering problem considering fixed-radius coverage constraint. Comput. Oper. Res. 2020, 119, 104936. [CrossRef]

25. Mokrini, A.; Boulaksil, Y.; Berrado, A. Modelling facility location problems in emerging markets: The case of the public healthcare sector in Morocco. Oper. Supply Chain Manag. Int. J. 2019, 12, 100-111. [CrossRef]

26. Church, R.L.; ReVelle, C.S. Theoretical and computational links between the p-median, location set-covering, and the maximal covering location problem. Geogr. Anal. 1976, 8, 406-415. [CrossRef]

27. de Assis Corrêa, F.; Lorena, L.A.N.; Ribeiro, G.M. A decomposition approach for the probabilistic maximal covering location-allocation problem. Comput. Oper. Res. 2009, 36, 2729-2739. [CrossRef]

28. Pereira, M.A.; Coelho, L.C.; Lorena, L.A.N.; De Souza, L.C. A hybrid method for the probabilistic maximal covering location-allocation problem. Comput. Oper. Res. 2015, 57, 51-59. [CrossRef]

29. Taymaz, S.; Iyigun, C.; Bayindir, Z.P.; Dellaert, N.P. A healthcare facility location problem for a multi-disease, multi-service environment under risk aversion. Socioecon. Plann. Sci. 2020, 71, 100755. [CrossRef]

30. Coco, A.A.; Santos, A.C.; Noronha, T.F. Formulation and algorithms for the robust maximal covering location problem. Electron. Notes Discret. Math. 2018, 64, 145-154. [CrossRef]

31. Doerner, K.F.; Gutjahr, W.J.; Hartl, R.F.; Karall, M.; Reimann, M. Heuristic solution of an extended double-coverage ambulance location problem for Austria. Cent. Eur. J. Oper. Res. 2005, 13, 325-340.

32. Lin, G.; Xu, H.; Chen, X.; Guan, J. An effective binary artificial bee colony algorithm for maximum set k-covering problem. Expert Syst. Appl. 2020, 161, 113717. [CrossRef]

33. Alizadeh, R.; Nishi, T. Dynamic $\mathrm{p}+\mathrm{q}$ maximal hub location problem for freight transportation planning with rational markets. Adv. Mech. Eng. 2019, 11. [CrossRef]

34. Muren, L.H.; Mukhopadhyay, S.K.; Wu, J.; Zhou, L.; Du, Z. Balanced maximal covering location problem and its application in bike-sharing. Int. J. Prod. Econ. 2020, 223, 107513. [CrossRef]

35. Dong, G.; Ma, J.; Wei, R.; Haycox, J. Electric vehicle charging point placement optimisation by exploiting spatial statistics and maximal coverage location models. Transp. Res. Part D Transp. Environ. 2019, 67, 77-88. [CrossRef]

36. Chauhan, D.; Unnikrishnan, A.; Figliozzi, M. Maximum coverage capacitated facility location problem with range constrained drones. Transp. Res. Part C Emerg. Technol. 2019, 99, 1-18. [CrossRef]

37. Kaveh, M.; Mesgari, M.S. Improved biogeography-based optimization using migration process adjustment: An approach for location-allocation of ambulances. Comput. Ind. Eng. 2019, 135, 800-813. [CrossRef]

38. Nilsang, S.; Yuangyai, C.; Cheng, C.Y.; Janjarassuk, U. Locating an ambulance base by using social media: A case study in Bangkok. Ann. Oper. Res. 2019, 283, 497-516. [CrossRef]

39. Berman, O.; Krass, D.; Drezner, Z. The gradual covering decay location problem on a network. Eur. J. Oper. Res. 2003, 151, 474-480. [CrossRef]

40. Drezner, Z.; Wesolowsky, G.O.; Drezner, T. The gradual covering problem. Nav. Res. Logist. 2004, 51, 841-855. [CrossRef]

41. Karasakal, O.; Karasakal, E.K. A maximal covering location model in the presence of partial coverage. Comput. Oper. Res. 2004, 31, 1515-1526. [CrossRef]

42. Berman, O.; Drezner, Z.; Krass, D. The multiple gradual cover location problem. J. Oper. Res. Soc. 2019, 70, 931-940. [CrossRef]

43. Khatami, M.; Salehipour, A. The gradual minimal covering location problem. Available SSRN 35227772020. [CrossRef]

44. Erdemir, E.T.; Batta, R.; Rogerson, P.A.; Blatt, A.; Flanigan, M. Joint ground and air emergency medical services coverage models: A greedy heuristic solution approach. Eur. J. Oper. Res. 2010, 207, 736-749. [CrossRef]

45. Zhang, B.; Peng, J.; Li, S. Covering location problem of emergency service facilities in an uncertain environment. Appl. Math. Model. 2017, 51, 429-447. [CrossRef]

46. Cordeau, J.F.; Furini, F.; Ljubić, I. Benders decomposition for very large scale partial set covering and maximal covering location problems. Eur. J. Oper. Res. 2019, 275, 882-896. [CrossRef]

47. Eiselt, H.A.; Marianov, V. Gradual location set covering with service quality. Socioecon. Plann. Sci. 2009, 43, 121-130. [CrossRef]

48. Berman, O.; Kalcsics, J.; Krass, D.; Nickel, S. The ordered gradual covering location problem on a network. Discret. Appl. Math. 2009, 157, 3689-3707. [CrossRef] 
49. Bagherinejad, J.; Bashiri, M.; Nikzad, H. General form of a cooperative gradual maximal covering location problem. J. Ind. Eng. Int. 2018, 14, 241-253. [CrossRef]

50. Farahani, R.Z.; Hassani, A.; Mousavi, S.M.; Baygi, M.B. A hybrid artificial bee colony for disruption in a hierarchical maximal covering location problem. Comput. Ind. Eng. 2014, 75, 129-141. [CrossRef]

51. Yin, P.; Mu, L. Modular capacitated maximal covering location problem for the optimal siting of emergency vehicles. Appl. Geogr. 2012, 34, 247-254. [CrossRef]

52. Alizadeh, R.; Nishi, T. A genetic algorithm for multi-period location problem with modular emergency facilities and backup services. Trans. Inst. Syst. Control Inf. Eng. 2019, 32, 370-377. [CrossRef]

53. Sonego, M.; Echeveste, M.E.S.; Debarba, H.G. The role of modularity in sustainable design: A systematic review. J. Clean. Prod. 2018, 176, 196-209. [CrossRef]

54. Addis, B.; Carello, G.; Ceselli, A. Exactly solving a two-level location problem with modular node capacities. Networks 2012, 59, 161-180. [CrossRef]

55. Guha-Sapir, D. EM-DAT: The Emergency Events Database Université Catholique de Louvain (UCL); CRED: Brussels, Belgium, 2020; Available online: www.emdat.be/ (accessed on 9 October 2020).

56. Altay, N.; Green, W.G., III. OR/MS research in disaster operations management. Eur. J. Oper. Res. 2006, 175, 475-493. [CrossRef]

57. Available online: https://www.citypopulation.de/JapanCities.html (accessed on 9 October 2020).

58. Gralla, E.; Goentzel, J.; Fine, C. Assessing trade-offs among multiple objectives for humanitarian aid delivery using expert preferences. Prod. Oper. Manag. 2014, 23, 978-989. [CrossRef]

(C) 2020 by the authors. Licensee MDPI, Basel, Switzerland. This article is an open access article distributed under the terms and conditions of the Creative Commons Attribution (CC BY) license (http://creativecommons.org/licenses/by/4.0/). 